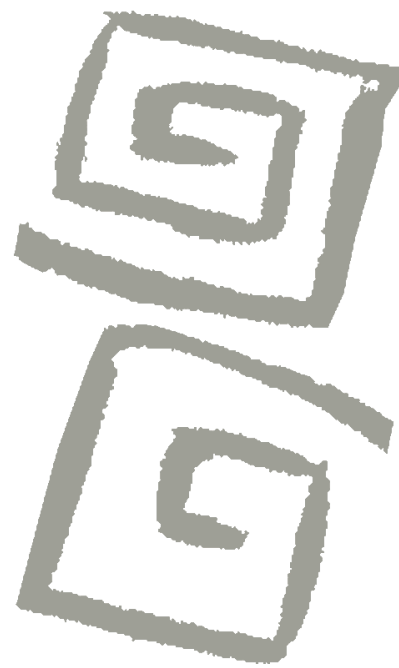

\title{
Valores percibidos en la publicidad de alimentos por jóvenes con y sin trastornos de la conducta alimentaria
}

\author{
The perception of values in food commercials on \\ the part of young people with and without eating \\ disorders
}

Mas-Manchón, Lluís ${ }^{1}$; Rodríguez-Bravo, Ángel ${ }^{2}$; Montoya-Vilar, Norminanda ${ }^{3}$; Morales-Morante, Fernando ${ }^{4}$;opes, Elaine ${ }^{5}$; Añaños, Elena ${ }^{6}$; Peres, Rafaella ; Martínez, María Eugenia ${ }^{8}$; Grau, Antoni ${ }^{9}$

'Doctor en Ciencias de la Comunicación. Profesor visitante, Universitat Pompeu Fabra, Barcelona, España. Lluis.Mas@upf.edu

${ }^{2}$ Doctor en Ciencias de la Comunicación. Profesor titular, Universitat Autònoma de Barcelona, España. angel.rodriguez@uab.es

${ }^{3}$ Doctora en Ciencias de la Comunicación. Profesora titular, Universitat Autònoma de Barcelona, España. norminanda. montoya@uab.es

${ }^{4}$ Doctor en Ciencias de la Comunicación. Investigador posdoctoral, Universitat Autònoma de Barcelona, España. fernando.morales@uab.es

DDoctora en Ciencias de la Comunicación. Profesora asociada, Universitat Autònoma de Barcelona, España. elaine.lopes@uab.es

${ }^{6}$ Doctora en Psicología. Profesora titular, Universitat Autònoma de Barcelona, España. elena.Añaños@uab.es

${ }^{7}$ Doctoranda de Comunicación. Investigadora visitante, Universidade Federal de Pernambuco, Brasil. rafaellaperes@hotmail.com

${ }^{8}$ Doctoranda de Comunicación, Universitat Autònoma de Barcelona, España. meugenia. mrtnz.snchz@gmail.com

${ }^{9}$ Licenciado en Psicología, Institut de Trastorns Alimentaris, España. tgrau@itacat.com
RESUMEN La publicidad utiliza imágenes corporales fuertemente estereotipadas para promocionar cánones físicos y conductas alimentarias no saludables asociadas a productos de alimentación dirigidos sobre todo a jóvenes. El objetivo de este estudio, realizado en Barcelona (España) durante el mes de mayo de 2013, es testear la percepción de 25 valores en siete spots televisivos de alimentación (con y sin estrategias de imagen corporal) en 139 jóvenes con y sin trastornos de la conducta alimentaria (TCA). Los resultados muestran que solo el grupo de jóvenes con TCA considera que los spots con una estrategia comercial basada en la imagen corporal influyen muy negativamente en valores como salud, bienestar, familia y esfuerzo. En cambio, se ha observado una gran coincidencia entre los dos grupos cuando se evalúa el resto de los spots. Estos resultados señalan que los jóvenes universitarios españoles de hoy han aceptado como normal un canon de belleza basado en el orden social y económico, mientras que los jóvenes en tratamiento por desórdenes alimenticios sí han aprendido a decodificar este tipo de mensajes.

PALABRAS CLAVES Trastornos de la Conducta Alimentaria; Publicidad de Alimentos; Valores de Referencia; Medios de Comunicación; España.

ABSTRACT Advertising uses stereotyped body images to promote physical ideals and unhealthy eating habits related to food products which are targeted especially at young people. The purpose of this study, carried out in Barcelona (Spain) in May 2013, was to test the perception of 139 young people of university age - with and without eating disorders - regarding 25 values in seven food commercials that did and did not use body image strategies. Results show that only the group of young people with eating disorders considered commercials using body image strategies to have a very negative influence on values such as health, well-being, family and effort. In contrast, the assessment of the two groups regarding the rest of the commercials greatly coincided. These results show that today's university youth have accepted as normal a beauty canon based on the prevailing social and economic order, while young people in treatment for eating disorders have learned to denaturalize such messages.

KEY WORDS Eating Disorders; Food Publicity; Reference Values; Communications Media; Spain. 


\section{INTRODUCCIÓN}

Algunas de las enfermedades más graves que acechan a las sociedades avanzadas son consecuencia de los trastornos en la conducta alimentaria (TCA), enfermedad mental que se manifiesta con comportamientos alimentarios no saludables. Aunque se trata de una enfermedad con importantes connotaciones psicológicas y abordada desde la psicología e incluso la psiquiatría, hay un gran consenso sobre la influencia que tienen en este tipo de alteraciones de la conducta factores externos, sociales y culturales (1); se trata de trastornos desarrollados en el seno de sociedades avanzadas, modernas y con las mejores condiciones de vida (2).

La mayoría de los expertos consideran que los trastornos de alimentación parecen estar potenciados por la presión de valores androcéntricos sobre las mujeres en la sociedad del culto al cuerpo (3). Con relación a los adolescentes, los datos de las investigaciones señalan que las causas de la anorexia y de la bulimia son múltiples. Así, los agentes genéticos son más importantes en la bulimia que en la anorexia; si bien, es innegable la influencia en su desarrollo de factores socioculturales como los hábitos de alimentación, la presión social ante el fenómeno de la belleza, los valores asociados a la estética de la delgadez y los modelos de los medios de comunicación (4).

\footnotetext{
El imaginario social colectivo está repleto de imágenes mediáticas propuestas por la publicidad en la que los cuerpos son presentados como perfectos, bellos, esbeltos y presumiblemente reales. (5 p.248)
}

Vivimos inmersos en una sociedad totalmente mediatizada, en la que los flujos comunicativos son múltiples, constantes y estructurales; en la que se ha impuesto una cultura de la imagen determinada por modelos y cánones físicos que sirven al sistema de mercado a través de miles de productos asociados a la apariencia de las personas. Todo este marco social, determinado por la productividad, el pragmatismo y la competitividad, parece influir con mucha fuerza en los TCA.

Este estudio trata la influencia de la publicidad en los trastornos de la conducta alimenticia y aboga por la necesidad de reforzar la vertiente de los valores en un ámbito de educación mediática.

\section{Trastornos alimentarios y publicidad}

La alteración de la conducta alimentaria se debe principalmente a una alteración en la percepción de la forma y el peso corporales Ilamada "dismorfofobia" (6). Aunque en cualquier trastorno mental psiquiátrico siempre hay una predisposición genética, según el modelo biopsicosocial de Lucas (7), consideramos que esta enfermedad no puede ni debe entenderse fuera del contexto social (8).

Según Ida y Silva (9), la relación que el individuo mantiene con su cuerpo ha evolucionado, acompañando importantes cambios en los hábitos de alimentación, en la configuración de los grupos sociales y en los vínculos interpersonales, dando lugar a un aumento de diagnósticos de la enfermedad. Por una parte, numerosos estudios constatan la insatisfacción general de las personas con su imagen corporal o autoimagen personal. Y por otra, esta insatisfacción parece manifestarse en forma de trastornos alimentarios en personas cada vez más jóvenes. Efectivamente, diferentes estudios indican que alrededor de un $40-50 \%$ de los niños de entre 6 y 12 años se sienten insatisfechos con su aspecto físico (10-14). Y estudios recientes como los de Bird et al. (15) asocian la baja valoración de la imagen corporal en niños y adolescentes a importantes problemas de salud física (reducción de la actividad física y patrones de conducta no saludables) y psicológica (depresión, ansiedad, problemas en las relaciones interpersonales). Los estudios constatan la existencia de ideales diferentes en función del género: las chicas tienden a desear un cuerpo más delgado, mientras que los chicos desean un físico más musculado con un mínimo de grasa corporal. Son principalmente las mujeres quienes reportan un mayor grado de insatisfacción con su cuerpo (16), aunque ambos géneros rechazan y estigmatizan la obesidad en busca de cuerpos con un mínimo de grasa corporal, lo que Claude Fischer ha Ilamado lipofobia de la sociedad actual (17).

Estos cánones lipofóbicos de la belleza están asociados con el éxito y la aceptación social, por lo que los medios de comunicación, principalmente basados en la imagen, fomentan esa clase 
de estereotipos corporales de género para publicitar la imagen corporal canónica de niños, adolescentes y jóvenes (18-21). La explotación de esta imagen responde a una estrategia comercial de sectores muy diferentes: el agroalimentario (con productos dietéticos, dietas, etc.), el de la moda (tallas, ropas, etc.), el de la salud (tratamientos, cirugías, implantes, medicación, etc.) e incluso el del deporte (fitness, gim, spas, etc.). El canon de belleza actual es, por tanto, una creación social, como resultado de una multitud de intereses comerciales (22). Esos intereses dirigen las preferencias y el gusto de la sociedad a través de una violencia simbólica que, en la actual sociedad mediatizada, puede llegar a tornarse angustiosa.

El actual canon de belleza es inalcanzable para la inmensa mayoría de la población. Este canon está basado en una mujer extremadamente delgada, blanca caucásica (incluso pálida o enfermiza), de clase media-alta (23), muy joven (adolescente o "Iolita") (24) y, no pocas veces, en actitud de trance o sometimiento sexual al hombre y con frecuentes alusiones a fantasías de tipo andrógino, zoófilo, sádico..., así como simbolizando violaciones u orgías $(25,26)$. Se constata, también, que las mujeres más expuestas a revistas y televisión muestran más insatisfacción con su cuerpo (27).

Y este canon se está extendiendo a la niñez: la sociedad difunde a través de los medios y la publicidad el canon de un niño delgado y muy activo, lo cual choca frontalmente con la constante promoción mediática de productos hipercalóricos que responde a otros intereses comerciales, con consecuencias graves sobre la salud $(28,29)$. La niñez es una etapa de crecimiento fundamental, por lo que es natural que el cuerpo tenga formas redondeadas justo antes de adoptar una constitución adulta al final de la adolescencia.

En particular, numerosos estudiosos han evidenciado los importantes trastornos alimentarios asociados a la publicidad en general $(30,31)$. Desde la década de1990 existen investigaciones $(32,33)$ que señalan a los medios de comunicación y a la publicidad como factores externos desencadenantes de los trastornos en la imagen corporal. Y durante las dos últimas décadas, se han multiplicado los estudios sobre la influencia de los contenidos publicitarios y de entretenimiento infantiles en la autoimagen corporal de los niños (34-37). Esta influencia va en aumento, pues en la actualidad los niños construyen cada vez más sus identidades dentro de una cultura mediática de consumo, por lo que se convierten en consumidores de todo tipo de productos desde edades muy tempranas (38). Se trata de productos que complementan la apariencia física, y que no pocas veces persiguen modificarla, para lo que utilizan estrategias que juegan con la insatisfacción y la aspiración de una apariencia ideal. La exposición a imágenes mediáticas y publicitarias de individuos idealmente delgados está comúnmente asociada a la preocupación por la imagen corporal. Los estereotipos visuales son una fuente importante de ideas simplificadas que pueden reforzar los prejuicios y convicciones tanto sobre otros como sobre el propio cuerpo. En particular, los medios promulgan el mensaje de que es bueno estar delgado; y el hecho de serlo se asocia con rasgos positivos como la popularidad, el aprecio, la actividad física, la inteligencia, etc., (39-41).

\section{Trastornos alimentarios y educación en valores}

En el preámbulo de la Constitución promulgada por la Organización Mundial de la Salud (OMS) en 1946, se define la salud como "un estado de completo bienestar físico mental y social, y no solamente la ausencia de afecciones o enfermedades" (42). Tradicionalmente, la familia y la escuela se han encargado de educar a las personas como ciudadanos íntegros y según una moral establecida y universal. En los centros educativos en general, se intenta educar a los niños según el respeto a valores como la dignidad, la responsabilidad o la solidaridad (43), y se les enseña a enfrentarse a las diferentes situaciones de la vida mediante valores específicos. De hecho, al menos desde la institución escolar, se realiza un gran trabajo en el fomento de este concepto global y positivo de salud en forma de valores como el aprecio por la higiene, la variedad y riqueza de los alimentos o el respeto y cuidado general del cuerpo (44). Recientes investigaciones han localizado pequeños problemas conectados con la imagen corporal durante la infancia, y plantean medidas educativas concretas, como la formación en valores en el seno de la familia y en ámbitos como la guardería (45). Esta línea de trabajo, 
que vincula valores sociales y educativos con un concepto amplio de salud, se inicia con la lista de valores sugerida por Kahle, Beatty y Homer (46): sentido de pertenencia, diversión y disfrute en la vida, relaciones afectuosas, autosatisfacción, respeto, emoción, sentido del cumplimiento, seguridad y respecto a uno mismo. En este sentido, Grunert (47) parte de las necesidades básicas y motivaciones de Maslow (48) e intenta estudiar los valores relacionados con los trastornos alimentarios en la cultura alemana. El autor utiliza en sus investigaciones el Dutch Eating Behaviour Questionnaire (Cuestionario holandés sobre la conducta alimentaria) (49), una herramienta basada en valores que sirve para estudiar la conducta alimentaria y los desórdenes alimentarios, adaptada a la sociedad alemana (Fragebogen Ernährungsverhalten FEV). Grunert (50) proponía un estudio empírico para poder verificar la hipótesis que relacionaba conducta alimentaria, valores y personalidad, es decir, planteaba que los valores reflejan déficits personales y se correlacionan con conductas alimentarias desordenadas compensatorias. La falta de "seguridad", por ejemplo, está asociada con estrategias alimentarias que tienden a autoafirmar al individuo, lo que apoya la tesis de que los valores pueden ser un buen indicador de la influencia publicitaria en este sentido. Por lo tanto, se formula la hipótesis general en estos términos:

- H1. La percepción de los valores sociales, educativos y humanos en los spots televisivos de alimentación por parte de sujetos con TCA es diferente a la percepción de sujetos sin TCA.

La organización Consumers International $(\mathrm{Cl})$ desarrolló una investigación con consumidores de todo el mundo (51) analizando diversos aspectos relacionados con los valores de la publicidad de cereales. El estudio considera irresponsable la utilización de dibujos animados y personajes fuertemente estereotipados para la promoción de productos alimentarios que no fomenten hábitos de alimentación saludables. Este estudio vincula la publicidad con valores como la aventura, el juego, la fuerza, el afecto, la familia, la salud, la felicidad, la energía, la inteligencia, la concentración o el deporte. Aunque incipiente, esta línea parece dividirse entre la investigación aplicada a la identificación y prevención de conductas no saludables mediante el análisis de valores personales y la investigación sobre la presencia de valores en los medios y la publicidad.

Los medios en general y la publicidad en particular son una suerte de espejo de la sociedad (52-54), pues absorben la realidad al tiempo que contribuyen a construirla (55-57). En cierto sentido, dependen de un orden social, económico o cultural, afectado por una importante crisis de valores, representado y estimulado en los medios y sintetizado en la publicidad $(58,59)$. En general, los trastornos alimentarios son una enfermedad social o socializada (60) que la sociedad en general tiende a silenciar u obviar (61). Esto puede explicar que los jóvenes no sean capaces de detectar las causas sociales de este problema. Pero a ese silencio social debemos asociar, también, la normalización mediática del canon delgado y un deficiente entrenamiento para la decodificación mediática. Esta certeza está dirigiendo la investigación actual hacia un abordaje educacional integral del problema, con el objetivo de que los jóvenes con TCA sean capaces de discernir esta distorsión mediática y social. Este abordaje debe contemplar los valores éticos y morales universales (recogidos en documentos socialmente consensuados: declaración de los derechos humanos, constituciones nacionales y federales, etc.) y compatibilizarlos con una educación mediática que permita comprender en su totalidad la significación de los mensajes mediáticos. Lo que nos lleva a formular dos subhipótesis basadas en el tipo de publicidad, los valores que la definen y la evaluación del contenido del spot (favorable o desfavorable) respecto a estos valores:

- H1.1. La identificación de presencia de valores en un anuncio difiere en función de su contenido (grado de asociación entre delgadez y bienestar, salud o éxito) entre los jóvenes con TCA y los jóvenes sin TCA.

- H.1.2. La evaluación de un anuncio como favorable, o contrario, a cada uno de los valores identificados en ese mismo anuncio difiere en función de su contenido y en función de que los jóvenes que los evalúan padezcan, o no, TCA. 


\section{METODOLOGÍA Y BASES CONCEPTUALES}

\section{Procedimiento}

Se aplicó un diseño quasi-experimental durante el mes de junio de 2013 en el que se pasaron siete spots de alimentación a dos grupos de sujetos con y sin TCA de Barcelona. Inmediatamente después de cada spot, los sujetos respondieron a un cuestionario sobre la recepción de 25 valores. Hemos bautizado este cuestionario como Protocolo de Evaluación de Valores o "Protocolo Eva".

El Protocolo Eva define, en primer lugar, un inventario de 25 valores: amistad, bienestar, cooperación, cultura, deberes, democracia, derechos, dignidad, educación, esfuerzo, familia, justicia/ equidad, igualdad, independencia, intimidad, justicia, libertad, moral/honor, orden, paz, pluralismo, salud, responsabilidad, progreso, y respeto.

El concepto de valor ha sido definido de forma muy diversa en los últimos años y por parte de diferentes autores. Rokeach lo define como la "creencia duradera donde un modo de conducta o un estado último de existencia es personal y socialmente preferible a un opuesto modo de conducta o estado final de existencia" (62 p.5); mientras que Schwartz los define como los "objetivos transituacionales deseables, que varían en importancia y que sirven como principio de guía en las vidas de las personas" (63 p.2).

Con el objeto de adaptar el concepto de "valor" a los productos comunicativos, lo definiremos del siguiente modo:

\footnotetext{
...aquellos elementos de sus contenidos y aquellos rasgos de sus características formales que configuran el conjunto de cualidades que otorgan importancia, validez o mérito a una producción comunicativa, haciéndola ser apreciada por su adaptación a las necesidades del hombre y la sociedad. (64 p.168).
}

Cada valor se desarrolla en tres dimensiones (64 p.172):

1. Dimensión educativa: contenido dirigido a perfeccionar las facultades intelectuales, morales y físicas del ser humano.

2. Dimensión humana: contenido dirigido a la defensa de la dignidad, la satisfacción de las necesidades y el desarrollo físico y mental del ser humano.

3. Dimensión social: contenido dirigido a apoyar la inserción, la defensa de los derechos y la difusión de los deberes del ser humano en las organizaciones sociales.

Como se ve, existe la dimensión educativa de cada valor, y también el valor educación como tal. El valor educación se centra en aquellos aspectos del mensaje publicitario que atañen al sistema educativo, por lo que definimos el valor como la representación, argumentación o presencia de información favorable o que estimula la acción y el efecto de desarrollar la capacidad física, intelectual y moral del ser humano por medio de la enseñanza. Por su parte, la dimensión educativa de cada valor se centra en los aspectos basados en las facultades intelectuales, morales y físicas del ser humano, independientemente de los centros de formación o de un sistema reglado de educación.

Hay otros valores del inventario cuyos campos semánticos podrían solaparse, como es el caso de salud y el bienestar. Tal y como se argumentó anteriormente (65), se acotan las definiciones de cada valor respecto del resto. Así, según el glosario creado, la salud es la representación, argumentación o presencia de información favorable o que estimula el buen estado físico o moral propio así como el de cualquier ser vivo o colectividad; y el bienestar se define como la representación, argumentación o presencia de información favorable o que estimula la creación de condiciones materiales y sociales capaces de proporcionar las cosas necesarias para vivir bien y una existencia agradable en sociedad. Es decir, la salud se refiere a un estado físico y moral del ser humano o conjunto de seres humanos, mientras que el bienestar se refiere a las condiciones materiales y sociales que le/les permiten vivir bien en sociedad.

Este inventario ha sido testeado en el ámbito iberoamericano (65) y parte de una formalización positiva del concepto de valor basada en el análisis de tres documentos políticos de vocación universal y distinto origen cultural: la Declaración Universal de Derechos Humanos de Naciones Unidas, la Constitución Federal de Brasil y la Constitución Española.

Para evaluar la presencia de cada valor en un anuncio, primero el sujeto debe responder, valor 
a valor, si percibe su presencia en el mensaje, o no, y a continuación asignarle una valoración que indique la intensidad con la que lo percibe sobre una escala de 7 grados, basada en el diferencial de Osgood (65). En esta escala, el sujeto decide si el contenido del spot es favorable o desfavorable al valor que se está analizando. Esta respuesta se codificará, luego, como: $-3,-2,-1,0,1,2,3$. El conjunto global de respuestas de todos los sujetos que responden al test es analizado mediante un algoritmo que arroja un número racional, también dentro de un rango entre -3 y 3 . Este dato expresa el peso relativo de cada uno de los valores en el spot. La suma ponderada de esos pesos relativos permite, finalmente, medir la carga global de valores en cada spot. El algoritmo se calcula del siguiente modo:

1. Medida de la presencia relativa de cada valor: el índice que obtenemos con este procedimiento es la "intensidad de valor" y nos permite estimar la importancia relativa de cada valor y, también, comparar el tipo de recepción de los valores de un mismo spot por distintos grupos de sujetos. Para calcularlo, del conjunto de datos de intensidad asignados a un valor (ente $-3 \mathrm{a}+3$ ) por todos los sujetos que evalúan un spot obtendremos la moda; y la moda de cada valor será ponderada por su confiabilidad. Definimos la confiabilidad como el grado de coincidencia de todos los sujetos en la elección de la intensidad de un valor concreto. Se calcula dividiendo el número de respuestas iguales entre el número total de respuestas obtenidas (sujetos). La máxima confiabilidad supondría que todos los sujetos hubieran respondido de la misma forma, otorgando la misma intensidad al valor, en cuyo caso la confiabilidad de la moda sería la máxima posible, es decir 1. Si no hay coincidencia alguna, la confiabilidad sería 0; por ejemplo, una confiabilidad de 0,5 indicaría una coincidencia de la mitad de los sujetos en la elección de esa moda. Así, la intensidad (de $-3 a+3$ ) obtenida por cada valor es multiplicada por el valor de la confiabilidad, de esta forma, la intensidad de cada valor queda ponderada por la mayor o menor coincidencia entre los sujetos en las respuestas. Así: [intensidad de valor $=$ moda $\times$ confiabilidad $]$

2. Medida de la presencia global de valores: este segundo procedimiento de análisis genera un índice ponderado que nos informa de la presencia acumulada de valores en el spot. Para su cálculo basta sumar todas las "intensidades de valor" y dividir el resultado entre el total de valores del inventario, es decir: 25. Este dato, que hemos denominado "carga global de valores" nos permite comparar entre sí distintos spots, en función de la carga global de valores que es capaz de transmitir cada uno de ellos. Lo formulamos como carga global: $\Sigma$ (intensidades de valor) $/ \mathrm{n}^{\circ}$ de intensidades de valor.

Para contrastar los resultados obtenidos mediante este protocolo desde una perspectiva estadística convencional, hemos aplicado la prueba $t$ de Student mediante el paquete estadístico SPSS.

Los resultados se presentarán utilizando el algoritmo creado ad hoc para el análisis de valores (Protocolo EVA) junto con la prueba t de Student. Se debe tener en cuenta, por una parte, que el Protocolo EVA hace un cálculo exacto e independiente de cada valor cuyos datos permiten calcular la moda, es decir, la respuesta coincidente que haya sido seleccionada mayoritariamente por los sujetos, por lo que solo se aplicará la t de Student a los valores con moda. Por otra parte, la t de Student busca diferencias significativas en las varianzas de cada valor evaluado por un grupo de sujetos o por otro, por lo que servirá, sobre todo, para determinar qué valores son evaluados de forma significativamente diferente en determinados spots.

En suma, los resultados deben mostrar: a) el grado de coincidencia en la elección de valores en cada spot; b) la intensidad con la que cada valor es percibido, particularmente el sentido de la valoración positiva o negativa (favorable o desfavorable) del contenido del spot respecto a cada valor. También se hará referencia a la carga global de valor, en tanto que este dato nos indica el grado de capacidad (positiva o negativa) del spot para transmitir valores.

\section{Materiales}

Para este estudio se utilizaron siete spots que estaban siendo emitidos en la televisión española y/o latinoamericana al momento de hacer el estudio (junio de 2013). El primer spot es de entrenamiento de los sujetos. Se trata de un spot sobre 
la maratón solidaria que anualmente organiza el canal público catalán (TV3), y que se basa en la transmisión de valores positivos: la solidaridad, la tolerancia y la amistad. Los siguientes 6 spots son de alimentación y han sido utilizados y categorizados por Casalé y Añaños (66). El segundo spot, de la marca Donuts, forma parte de una campaña corporativa para celebrar los 50 años de la marca, para lo que se utiliza el argumento de la frescura del producto y su producción tradicional y casera junto a la emotividad de la trama. El tercer spot, de Activia, está dirigido a las mujeres, a las que les transmite el mensaje de "libérate", una Ilamada a tener actitudes positivas y valientes ante la vida. La trama muestra a una mujer que al consumir el producto consigue salir de un laberinto y el texto del jingle que lo acompaña, basado en el claim "libérate", dice en una ocasión: "la felicidad va por dentro". El cuarto spot, de Special k, describe diferentes tipos de pantalones vaqueros mientras se muestran imágenes de las figuras estilizadas de unas modelos vestidas con estas prendas, mientras suena una música con ritmos modernos y sensuales. La voz en off enfatiza en un determinado momento: "tu arma de seducción" y, a continuación, nos habla de un programa de control calórico gratuito que acaba en la marca del vaquero donde aparece escrito: "Special k. Comienza a cuidar lo que comes". El quinto spot, de Florette, utiliza el argumento de la frescura de su producto (lechugas), para lo que muestra un comando de personas que buscan la lechuga más fresca en un campo de miles de ellas, la recolectan y la traen (envasada ya en una bolsa) a la casa de una mujer. El sexto spot, All Bran, argumenta que "cenar demasiado puede provocar que no te sientas bien al despertar", mientras la imagen muestra a un perro rechazado del cuarto de su malhumorado amo, quien le lanza una almohada. La voz en off recomienda cenar únicamente estos "deliciosos" cereales (con voz sensual) y se muestran planos cortos ralentizados de los cereales cayendo en el bol. Por último, la locución dice: “Así estarás más sano y te despertarás de mejor humor. Sentirse sano se nota. Cenar All Bran también". Y el último spot, nuevamente Special K, muestra a una joven radiante que por la mañana se sienta a desayunar y cuando está a punto de darle un mordisco a una pequeña ensaimada, su imaginación la traslada al "temido" momento de pesarse en la báscula, seguido del júbilo por haber bajado de peso y su conexión con imágenes felices en las que ella se muestra ante el espejo con pantalones y ropas ajustadas. La vuelta a la realidad presenta de nuevo a la protagonista rechazando, contenta y convencida, la ensaimada, y tomando la caja de cereales de una estantería, mientras la voz en off añade: "Una mala decisión puede hacerte perder todo lo que has logrado. Por eso, mantén tu figura fácilmente desayunando un delicioso plato de Special K cada mañana".

Se ha considerado como spots "con estrategia de imagen corporal" a aquellas publicidades que utilizan el cuerpo humano estereotipado y canónico y que basan su "reason why" en el aspecto corporal ideal. Se trata de los spot 4, 6 y 7 . Los otros tres spots ( 2,3 y 5 ) muestran a personas normales, tanto en sus características (anciano, adultos de constitución natural...) como en el tipo de tratamiento de la imagen (sin planos travelling de las figuras de los protagonistas o planos cortos a distintas zonas de su cuerpo). Durante la prueba experimental, los sujetos podían consultar un glosario en el que estaban disponibles las definiciones de los 25 valores, con sus tres dimensiones desglosadas.

\section{Sujetos participantes}

En el estudio participaron 139 jóvenes que pertenecían a dos grupos diferenciados: el primer grupo se componía de 66 sujetos (mujeres) con TCA, pacientes del Institut de Trastorns Alimentaris de Barcelona, con edades comprendidas entre los 18 y los 25 años. Los trastornos de estos sujetos eran anorexia no purgativa, bulimia purgativa y trastornos de la conducta alimentaria no especificado (TCANE). Los tres tipos de trastornos se refieren a desórdenes alimentarios y psicoperceptivos con causas sociales, por lo que constituyen un grupo de estudio homogéneo en relación con la percepción de valores en la publicidad. El segundo grupo estaba formado por 73 sujetos sin este tipo de problemas (sin trastornos diagnosticados), alumnos de la Universidad Autónoma de Barcelona, de los cuales 11 eran hombres (15\%) y 62 mujeres (89\%), con edades también comprendidas entre los 18 y los 25 años. Por tanto, el primer grupo se componía de un solo sexo (femenino), mientras que el segundo incluía ambos 
Grupo con TCA | Carga global $=\mathbf{0 , 2 6 4}$

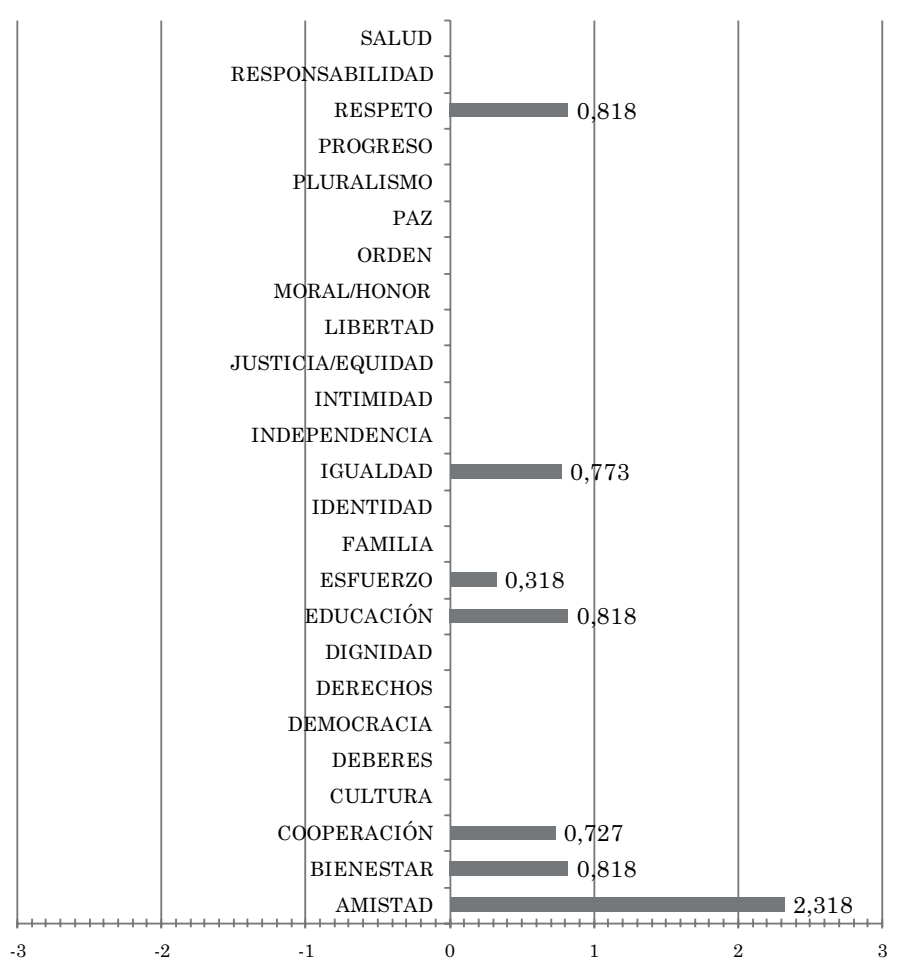

Grupo sin TCA | Carga global $=\mathbf{0 , 3 2 9}$

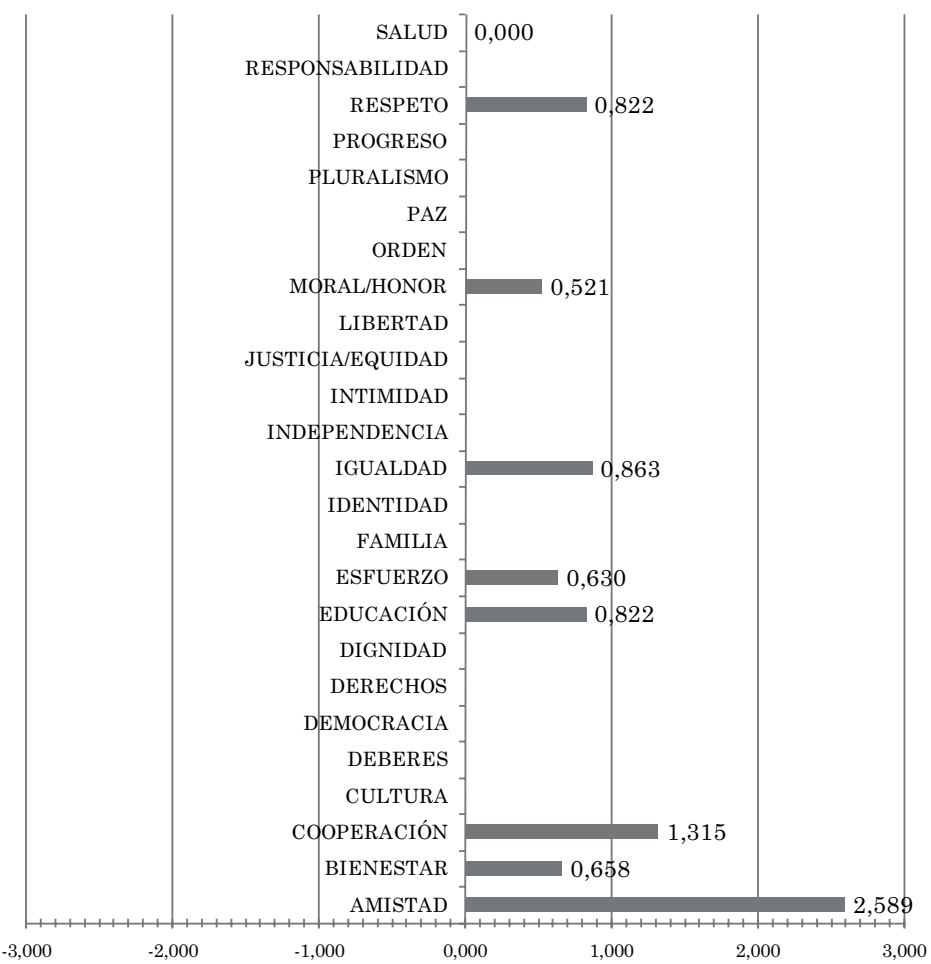

\section{Confiabilidad}

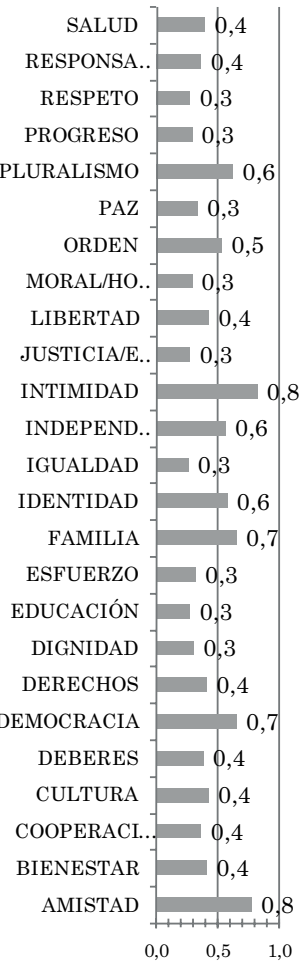

\section{Confiabilidad}

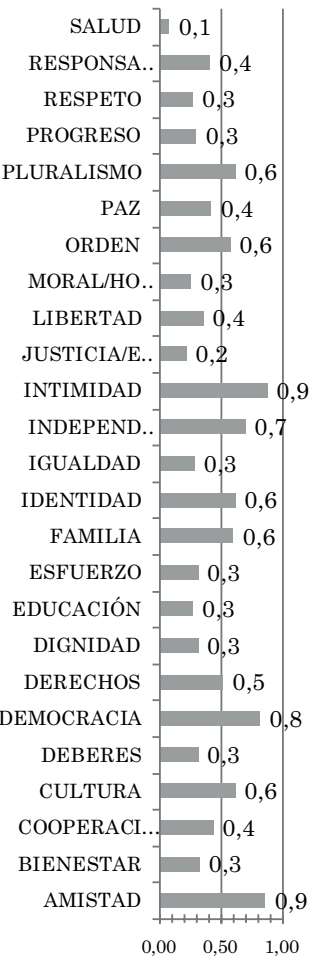

Figura 1. Carga global y confiabilidad del spot 1 (TV3), sobre el espectro de valores del Protocolo EVA, en grupos con y sin trastornos de la conducta alimentaria. Barcelona, 2013.

Fuente: Elaboración propia

TCA = Trastornos de la conducta alimentaria 
sexos, aunque mayormente el femenino. Esta diferencia no afecta a la aplicación ni al resultado del estudio, pues se trata de un test genérico que no hace referencia alguna a cuestiones de género.

Los participantes del Institut de Trastorns Alimentaris de Barcelona fueron contactados a través de Antoni Grau, jefe de Conocimiento e Investigación de ese instituto, y bajo el pleno conocimiento y consentimiento de las personas enfermas.

\section{RESULTADOS}

Como patrón general, ambos grupos (con y sin TCA) han coincidido en la elección de valores como definidores de los siete spots de la muestra con confiabilidades medias que van de 0,3 a 0,6, dependiendo de los valores y de los spots (cabe recordar que la confiabilidad es el grado de coincidencia en la elección y valoración del valor entre los sujetos; si hay unanimidad, la confiabilidad será 1, si coinciden el 50\%, la confiabilidad será de 0,5).

Hay dos rasgos que, en general, distinguen a ambos grupos. Por una parte, los jóvenes con TCA muestran menor sensibilidad a los valores. Por otra parte, en los spots con estrategias basadas en la imagen corporal, el grupo con TCA tiende a evaluar el contenido respecto a los valores clave (es decir, valores importantes para la temática de la publicidad sobre alimentos) como intensamente negativo, mientras que el grupo sin TCA valora los contenidos de los spots como moderadamente positivos.

En el primer spot (Figura 1), los sujetos con y sin TCA coinciden en siete valores percibidos de los 25 disponibles (respeto, igualdad, esfuerzo, educación, cooperación, bienestar y amistad). Asimismo, las valoraciones de estos siete valores son también bastante parecidas, por lo que la t de Student no es significativa en ningún valor. En particular, el valor amistad domina con puntuaciones positivas de 2,3 (con TCA) y 2,6 (sin TCA) respectivamente, y confiabilidades muy altas, del 0,8 y 0,9 . Los valores respeto, igualdad, educación y bienestar obtienen valoraciones positivas de 0,7 (con TCA) y 0,8 (sin TCA), con confiabilidades en torno a 0,3 . Las respuestas de los dos grupos de adolescentes difieren ligeramente en dos valores: esfuerzo, con un valor de 0,3 por parte de los jóvenes con TCA (confiabilidad 0,3) y un 0,6 por parte de los jóvenes sin TCA (confiabilidad 0,3), y cooperación, mejor valorada por los segundos con 1,3 (confiabilidad 0,4).

El segundo spot (Figura 2), de Donuts, presenta resultados similares al spot 1. En primer lugar, hay una coincidencia en la valoración positiva de cuatro valores (amistad, bienestar, cooperación y esfuerzo), aunque con una menor sensibilidad de parte de los jóvenes con TCA $(1 ; 0,5 ; 1,1 ;$ y 0,3 respectivamente) con relación a los jóvenes sin $\operatorname{TCA}(0,7 ; 0,3 ; 1,7 ;$ y 0,8 respectivamente), con confiabilidades en general entre 0,3 y 0,6 . Y, en segundo lugar, hay algunos valores que presentan diferencias, aunque la ausencia de una moda ha impedido que el Protocolo Eva los localizara. Se trata de los valores responsabilidad y progreso, que sí ha localizado la t de Student. Como se puede ver en el Cuadro 1, el grupo con TCA los valora significativamente peor que el grupo sin TCA. Tratándose de un producto tan calórico como los Donuts, tiene sentido el hecho de considerar su publicidad como no responsable y no tan conectada al progreso.

El tercer spot (Figura 3), Activia, sigue con el patrón del primero y segundo spot: ambos grupos de jóvenes seleccionaron los mismos valores y las intensidades de los valores son muy similares, ligeramente mayores en el caso de los jóvenes sin TCA. Asimismo, la carga global es el doble en los sujetos sin TCA $(0,194)$ que en los sujetos con TCA $(0,11)$. En particular, solo el valor salud aparece con diferencias notables en el grado de intensidad positiva asignada por parte de los jóvenes con TCA $(0,6)$ respecto de los jóvenes sin TCA $(1,6)$, y hay diferencias pequeñas en el caso de bienestar. El valor libertad no presenta grandes diferencias, como indica el gráfico y la no significancia estadística de la t de Student (Cuadro 1).

El cuarto spot, Special K (Figura 4), es el primero con una estrategia de imagen corporal $\mathrm{O}$ adelgazamiento, y de hecho presenta otro patrón de percepción de valores: mismos valores escogidos por parte de ambos grupos pero intensidades claramente contrapuestas. En particular, este spot presenta únicamente dos valores -salud y bienestar - evaluados de forma contrapuesta por los dos grupos (Cuadro 1). Además, la carga global del spot es negativa para los jóvenes con 
Cuadro 1. Carga, confiabilidad y significancia estadística para los valores coincidentes del Protocolo EVA en grupos con y sin trastornos de la conducta alimentaria. Barcelona, 2013.

\begin{tabular}{|c|c|c|c|c|c|c|c|c|}
\hline \multirow{3}{*}{ Valores } & \multicolumn{4}{|c|}{ Protocolo EVA } & \multicolumn{4}{|c|}{ t de Student } \\
\hline & \multicolumn{2}{|c|}{ Con TCA } & \multicolumn{2}{|c|}{ Sin TCA } & \multicolumn{2}{|c|}{ Con TCA } & \multicolumn{2}{|c|}{ Sin TCA } \\
\hline & Carga & Confiabilidad & Carga & Confiabilidad & Media & Valor $p$ & Media & Valor $p$ \\
\hline \multicolumn{9}{|l|}{ Spot 2} \\
\hline Responsabilidad & - & - & 0,8 & 0,4 & 1,37 & $<0,005$ & 1,98 & $<0,005$ \\
\hline Respeto & - & - & 0,6 & 0,3 & 1,73 & 0,198 & 1,42 & 0,198 \\
\hline Progreso & - & - & 0,7 & 0,3 & 0,64 & $<0,005$ & 1,51 & $<0,005$ \\
\hline \multicolumn{9}{|l|}{ Spot 3} \\
\hline Salud & 0,6 & 0,3 & 1,6 & 0,5 & $-0,87$ & $<0,000$ & 1,38 & $<0,000$ \\
\hline Bienestar & 1,3 & 0,4 & 1,7 & 0,6 & $-0,41$ & $<0,000$ & 1,89 & $<0,000$ \\
\hline Libertad & 1,1 & 0,4 & 1,6 & 0,6 & 1,59 & $<0,050$ & 2,29 & $<0,050$ \\
\hline \multicolumn{9}{|l|}{ Spot 4} \\
\hline Salud & $-1,0$ & 0,3 & 0,0 & 0,2 & 1,48 & $<0,001$ & 2,32 & $<0,001$ \\
\hline Bienestar & $-0,7$ & 0,2 & 0,3 & 0,3 & 1,19 & $<0,001$ & $-0,41$ & $<0,001$ \\
\hline \multicolumn{9}{|l|}{ Spot 5} \\
\hline Bienestar & 0,6 & 0,3 & 0,7 & 0,4 & 1,38 & 0,287 & 1,60 & 0,287 \\
\hline Salud & 0,8 & 0,3 & 1,2 & 0,4 & 1,53 & 0,001 & 2,23 & 0,001 \\
\hline Cooperación & - & - & 0,5 & 0,3 & 1,56 & 0,119 & 1,20 & 0,119 \\
\hline \multicolumn{9}{|l|}{ Spot6 } \\
\hline Salud & $-0,4$ & 0,2 & 0,8 & 0,4 & $-0,80$ & $<0,000$ & 1,68 & $<0,000$ \\
\hline Familia & 0,2 & 0,2 & 0,8 & 0,4 & 0,94 & $<0,050$ & 1,64 & $<0,050$ \\
\hline Bienestar & 0,5 & 0,2 & 1,1 & 0,4 & 0,68 & $<0,000$ & 2,07 & $<0,000$ \\
\hline \multicolumn{9}{|l|}{ Spot 7} \\
\hline Salud & $-1,5$ & 0,5 & 0,2 & 0,6 & $-1,55$ & $<0,000$ & 0,24 & $<0,000$ \\
\hline Esfuerzo & $-1,0$ & 0,3 & 0,4 & 0,2 & $-0,88$ & $<0,050$ & 0,34 & $<0,050$ \\
\hline Bienestar & $-1,0$ & 0,3 & 0,2 & 0,2 & $-1,15$ & $<0,050$ & $-0,29$ & $<0,050$ \\
\hline
\end{tabular}

Fuente: Elaboración propia.

TCA $=$ Trastornos de la conducta alimentaria

Nota = En este cuadro no fue incluido el spot 1 dado que la $t$ de Student no fue estadísticamente significativa en ningún valor.

TCA $(-0,067)$ y muy ligeramente positiva para los jóvenes sin TCA $(0,014)$.

En el quinto spot (Figura 5) -de alimentación pero sin estrategia de imagen corporal- aparecen los mismos dos valores anteriores, salud y bienestar, pero en este caso evaluados positivamente de forma parecida por ambos grupos (patrón común con los otros spots sin estrategia de imagen corporal: spots 1,2 , y 3 ), sobre todo bienestar, valorada con un 0,6 por parte del grupo con TCA (confiabilidad $0,3)$ y como 0,7 por parte del grupo sin TCA (confiabilidad 0,4), y no tanto salud, 0,8 por parte del grupo con TCA (confiabilidad 0,3) y 1,2 por parte del grupo sin TCA (confiabilidad 0,4). Es por eso que la t de Student para varianzas iguales solo considera significativa la segunda (Cuadro 1). Además, únicamente el grupo sin TCA percibe el valor cooperación, no localizado por la t de Student.
El sexto spot, de All Bran (Figura 6) incide en la estrategia creativa de guardar la línea, aunque no directamente adelgazar. Así, la selección de valores de ambos grupos es idéntica (salud, familia y bienestar), mientras que su intensidad es opuesta en el caso de salud: - 0,4 del grupo con TCA frente a 0,8 del grupo sin TCA (confiabilidades 0,18 y 0,4 respectivamente), mientras que es ligeramente diferente en el caso de familia y bienestar (Cuadro 1).

El último spot, de Special K (Figura 7) es el que más claramente aboga por el argumento de adelgazar, y los resultados son claros de acuerdo al patrón de percepción de valores en los spots con estrategia de imagen corporal: ambos grupos de sujetos coinciden de nuevo en la selección de los tres valores presentes (salud, esfuerzo y bienestar), pero con intensidades de signo opuesto (Cuadro 1). 
Grupo con TCA | Carga global $=\mathbf{0 , 1 1 4}$

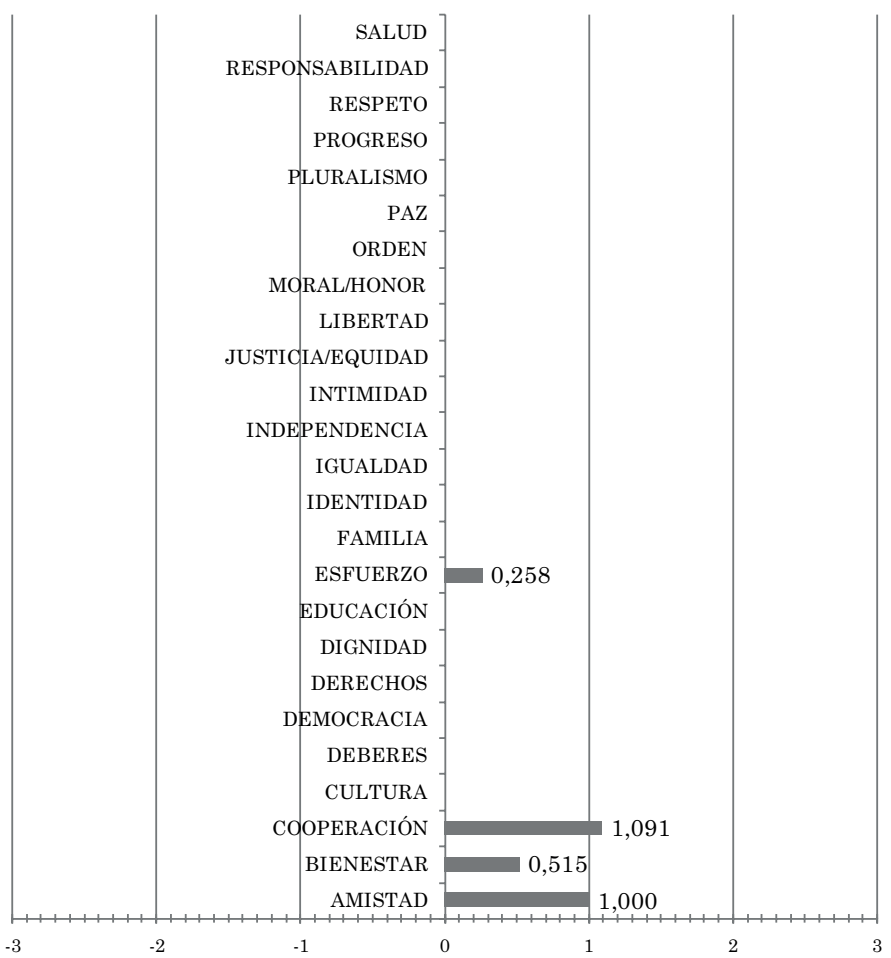

Grupo sin TCA | Carga global $=\mathbf{0 , 2 3 0}$

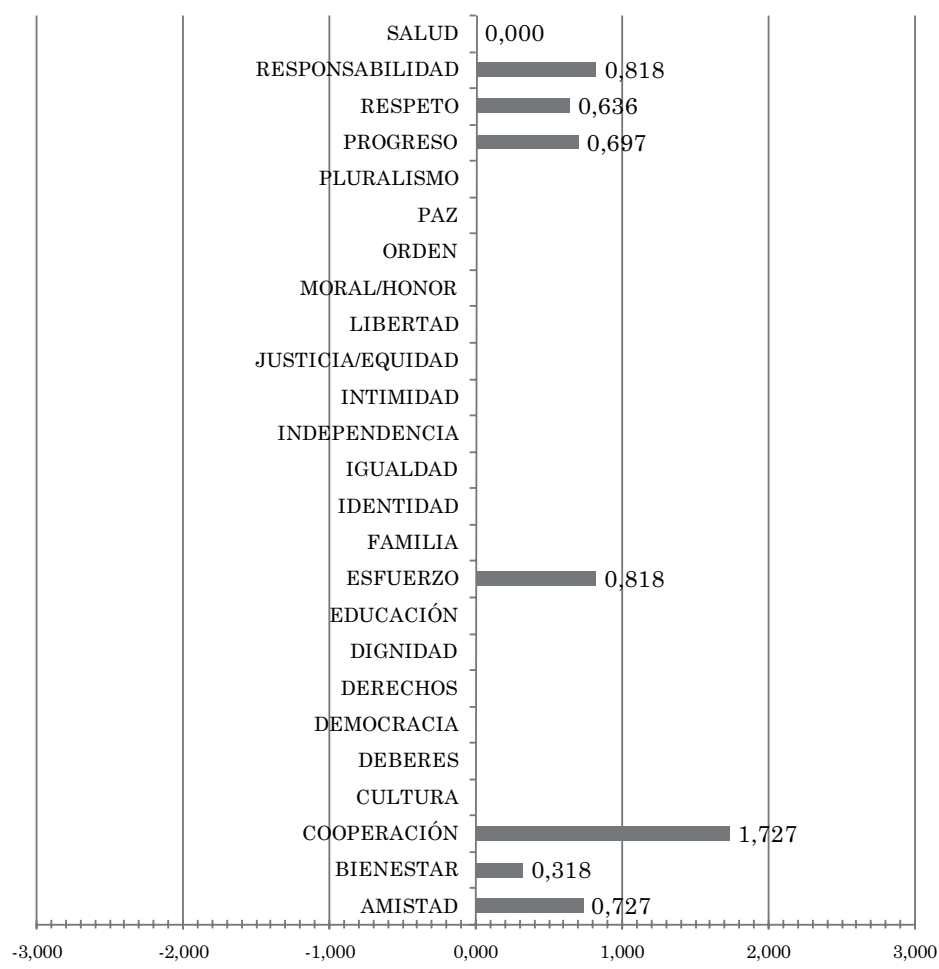

\section{Confiabilidad}

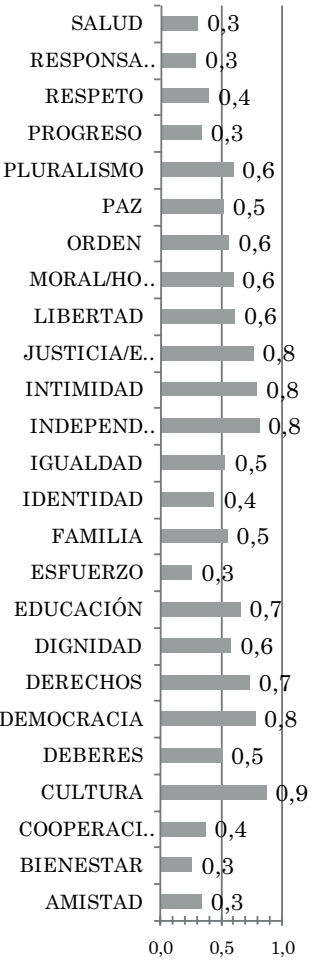

\section{Confiabilidad}

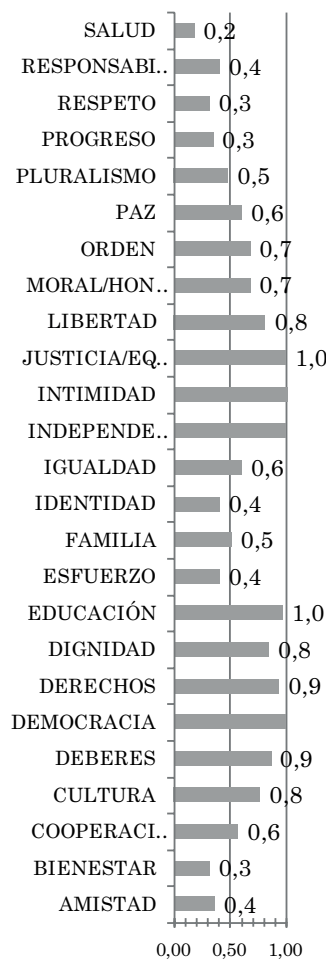

Figura 2. Carga global y confiabilidad del spot 2 (Donuts), sobre el espectro de valores del Protocolo EVA, en grupos con y sin trastornos de la conducta alimentaria. Barcelona, 2013. 
Grupo con TCA | Carga global $=0,117$

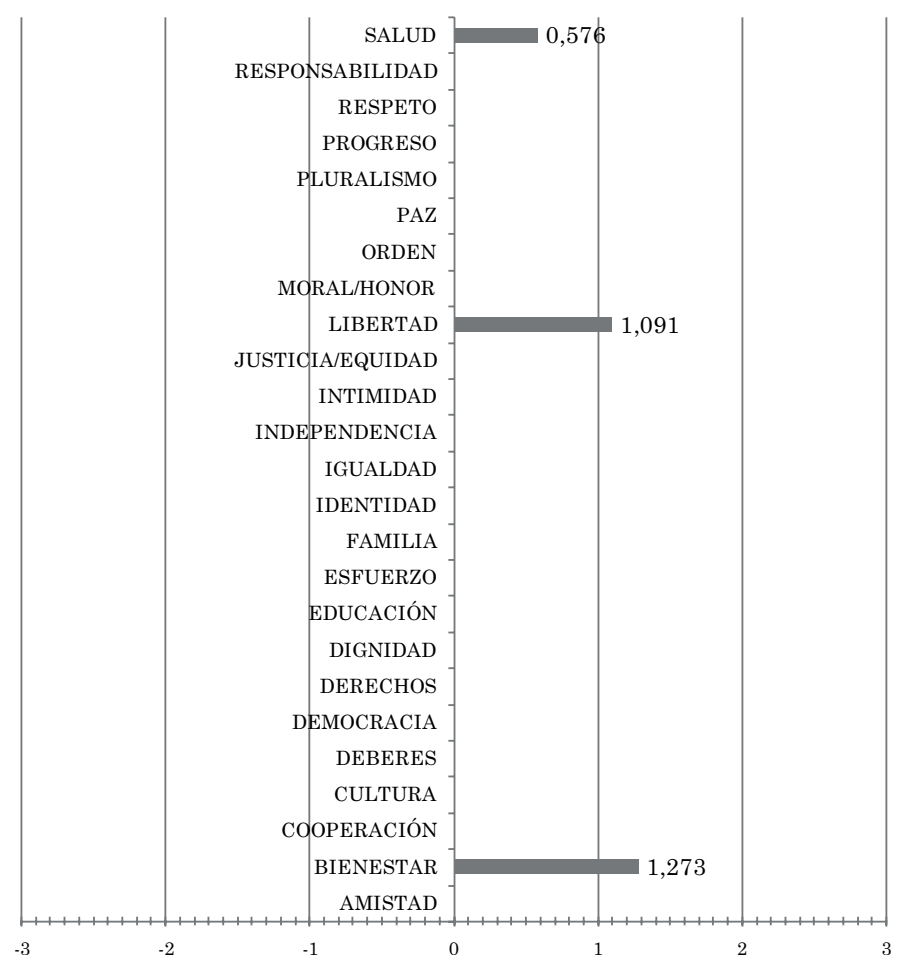

Grupo sin TCA | Carga global $=\mathbf{0 , 1 9 4}$

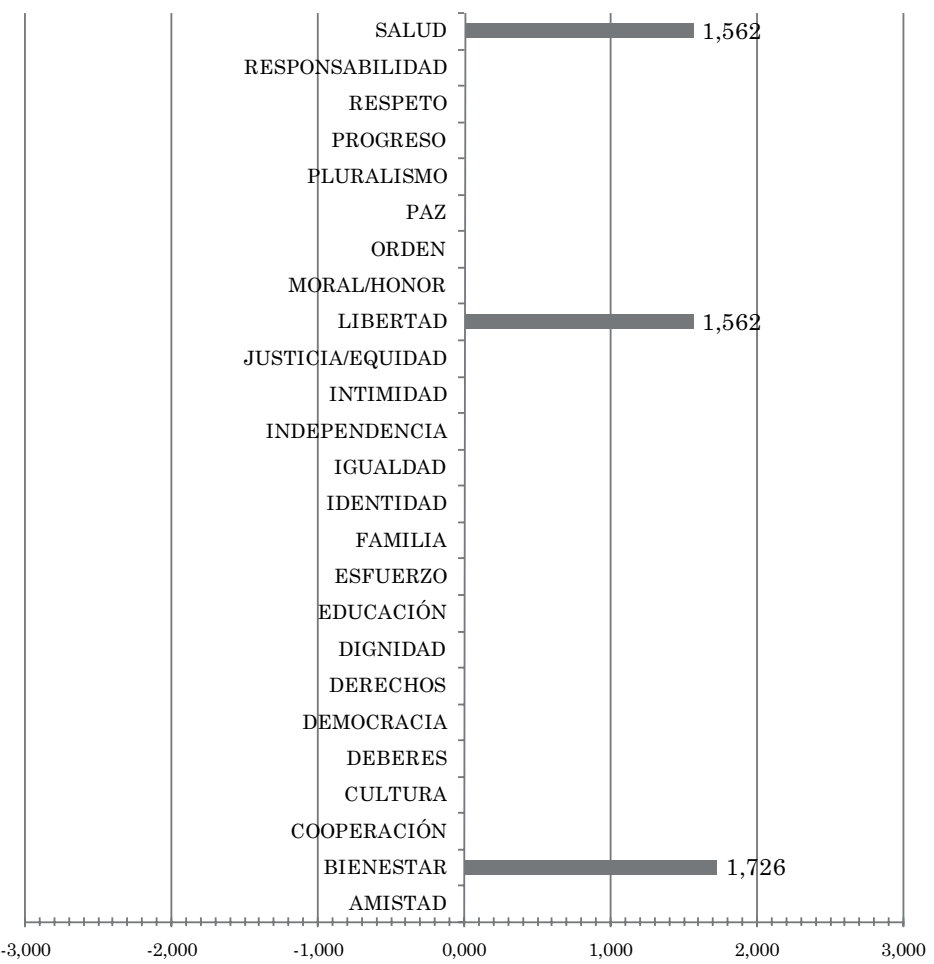

\section{Confiabilidad}

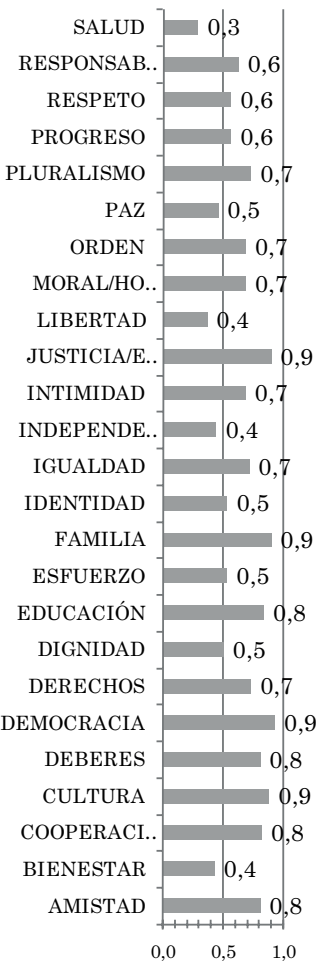

\section{Confiabilidad}

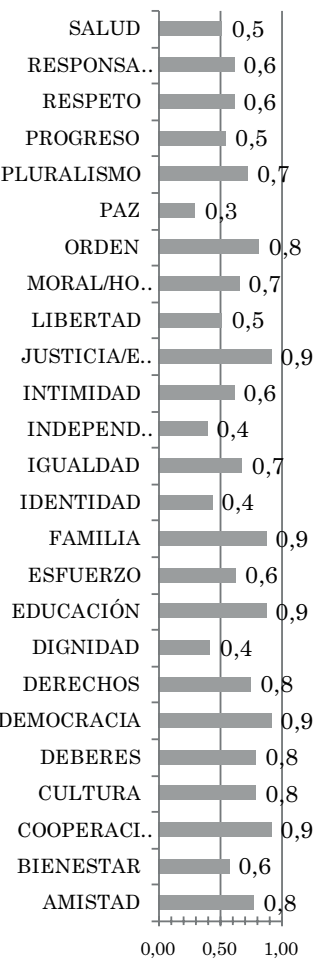

Figura 3. Carga global y confiabilidad del spot 3 (Activia), sobre el espectro de valores del Protocolo EVA, en grupos con y sin trastornos de la conducta alimentaria. Barcelona, 2013.

Fuente: Elaboración propia.

TCA = Trastornos de la conducta alimentaria 
Grupo con TCA | Carga global $=-0,067$

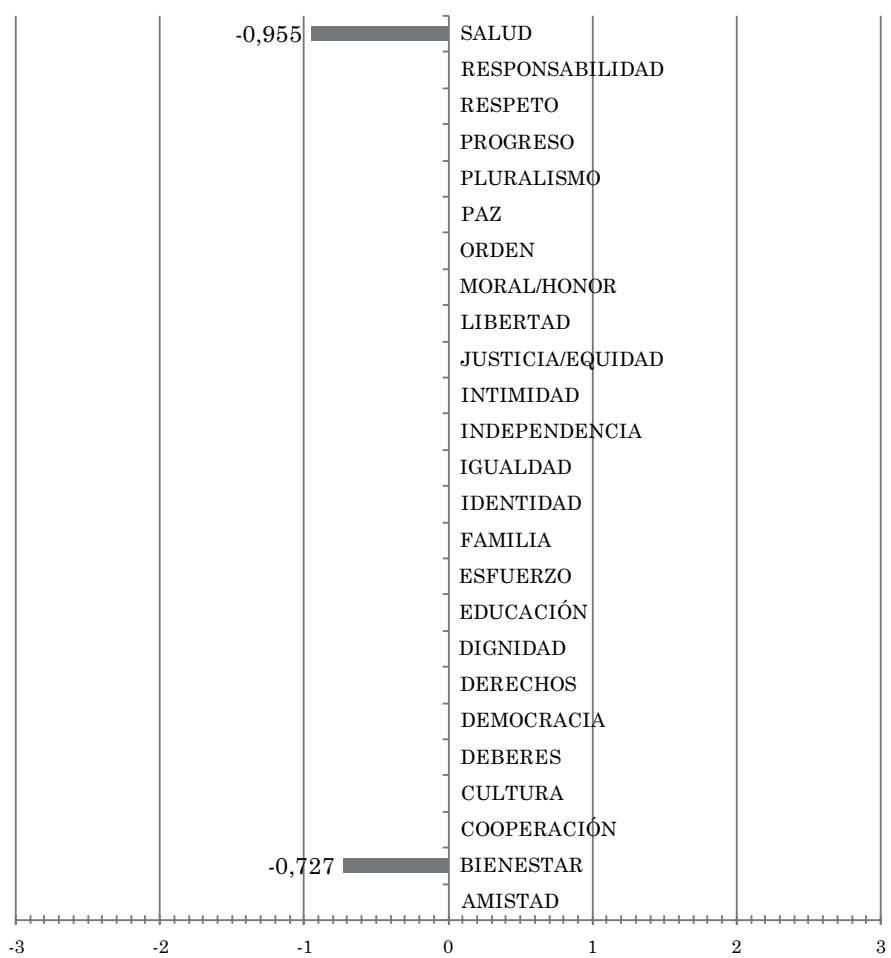

Grupo sin TCA | Carga global $=\mathbf{0 , 0 1 4}$

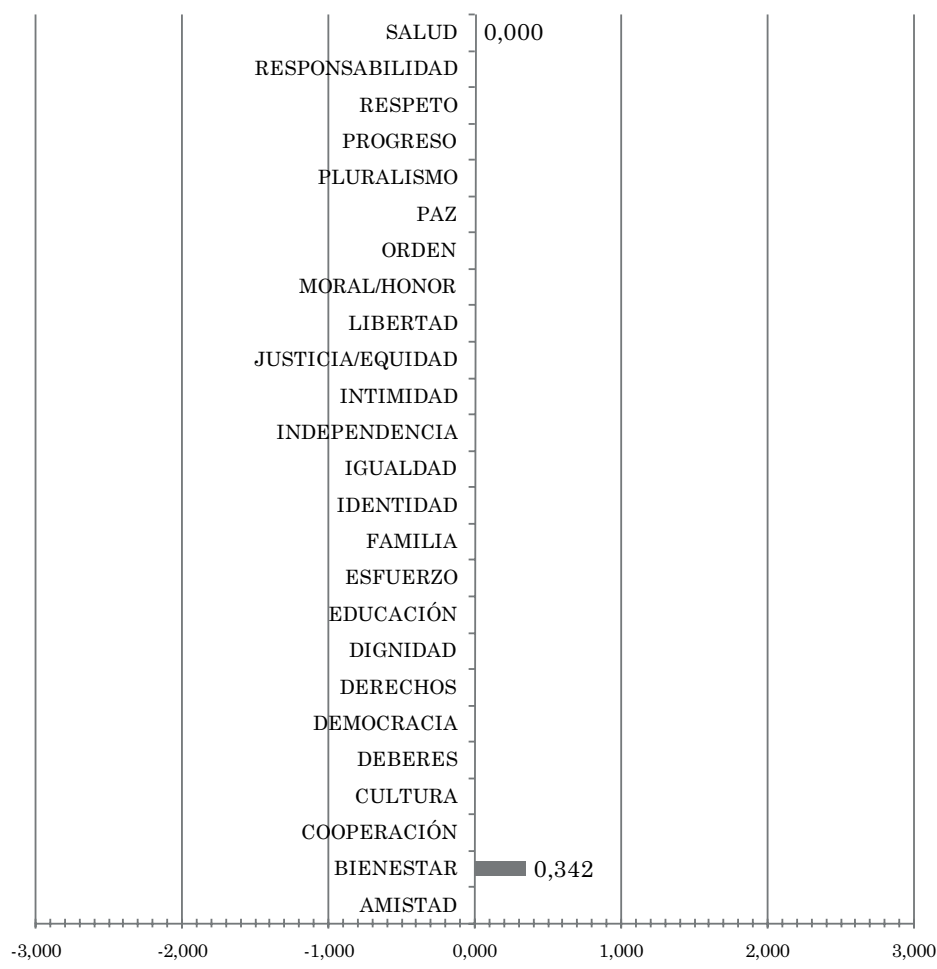

\section{Confiabilidad}

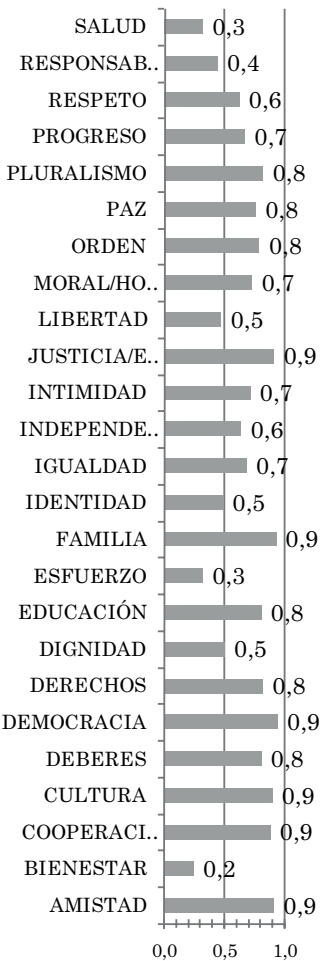

\section{Confiabilidad}

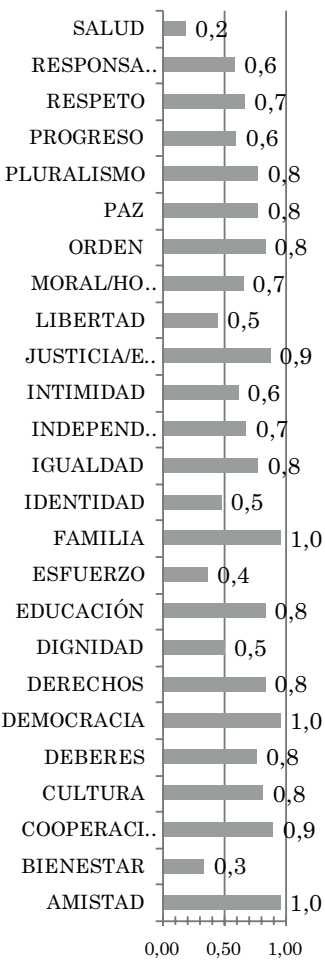

Figura 4. Carga global y confiabilidad del spot 4 (Special K), sobre el espectro de valores del Protocolo EVA, en grupos con y sin trastornos de la conducta alimentaria. Barcelona, 2013.

Fuente: Elaboración propia.

TCA = Trastornos de la conducta alimentaria. 
Grupo con TCA | Carga global $=\mathbf{0 , 0 5 8}$

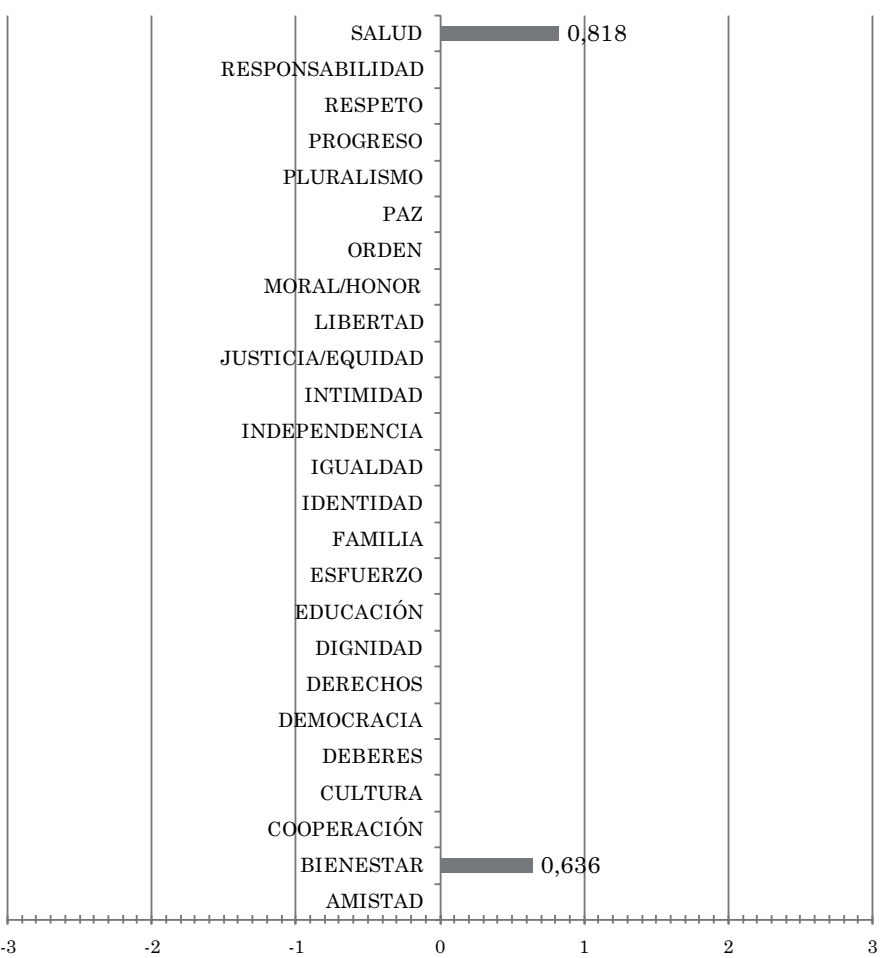

Grupo sin TCA | Carga global $=0,101$

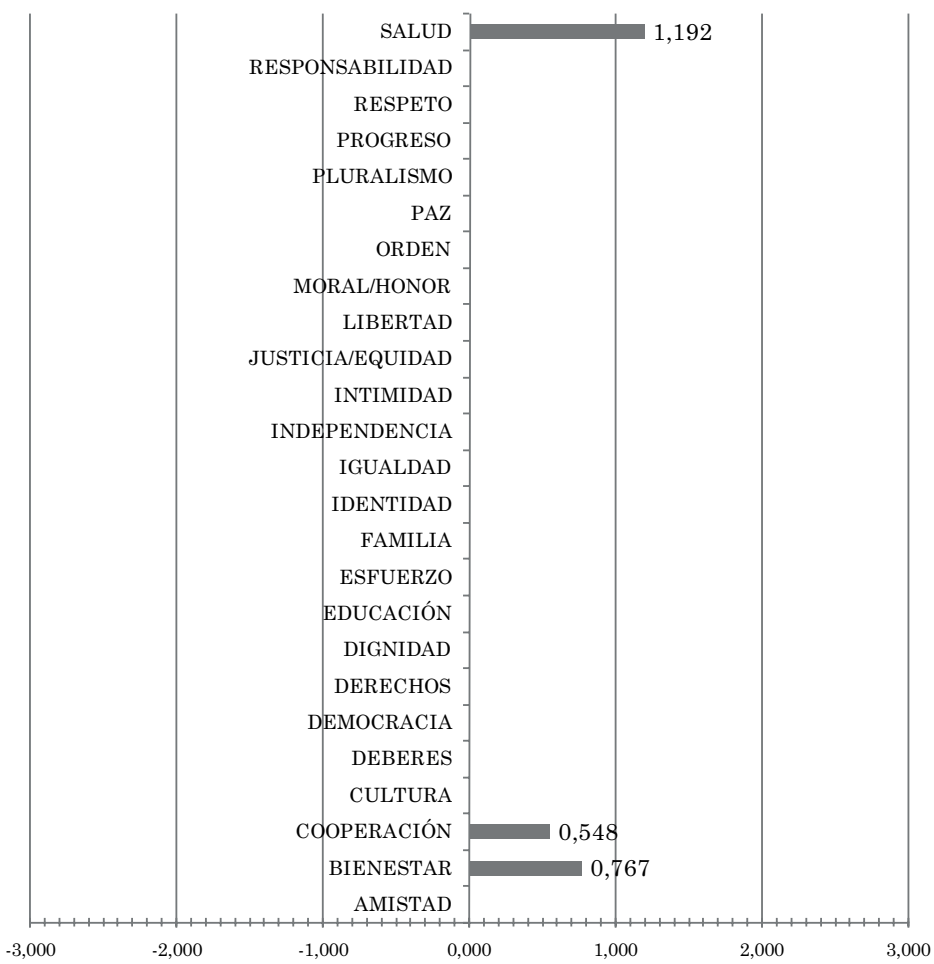

\section{Confiabilidad}

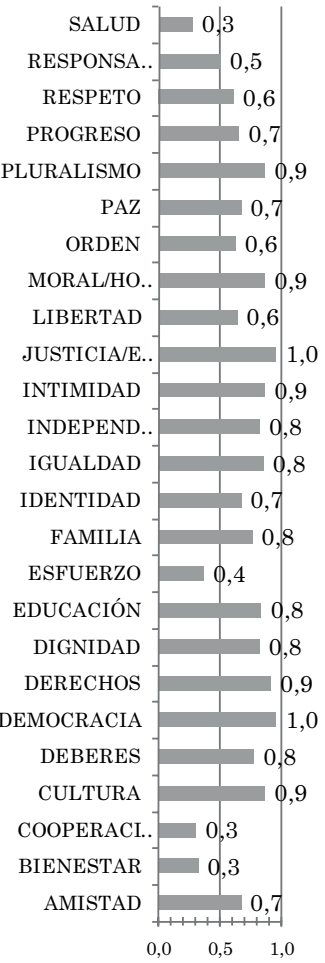

\section{Confiabilidad}

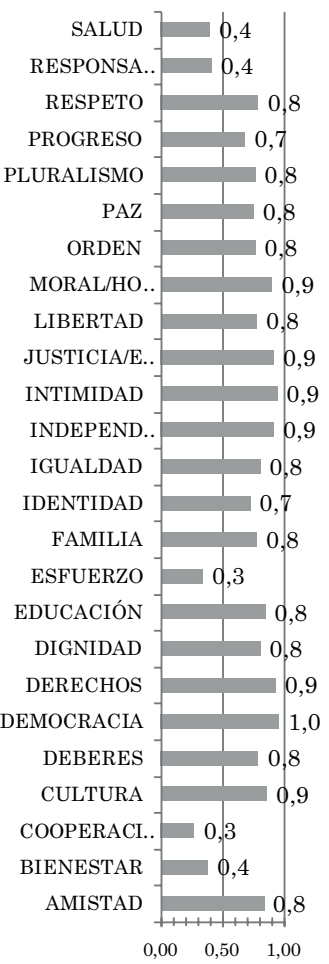

Figura 5. Carga global y confiabilidad del spot 5 (Florette), sobre el espectro de valores del Protocolo EVA, en grupos con y sin trastornos de la conducta alimentaria. Barcelona, 2013.

Fuente: Elaboración propia.

TCA = Trastornos de la conducta alimentaria 
Grupo con TCA | Carga global $=\mathbf{0 , 0 1 3}$

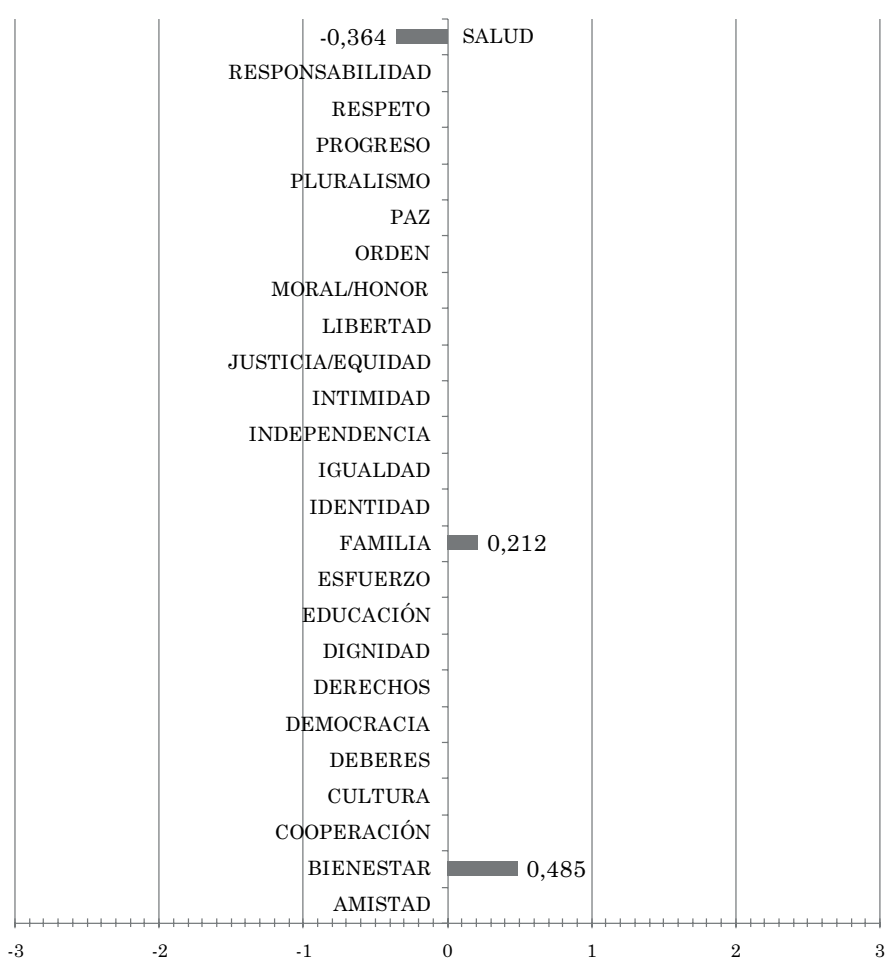

Grupo sin TCA | Carga global $=\mathbf{0 , 1 0 9}$

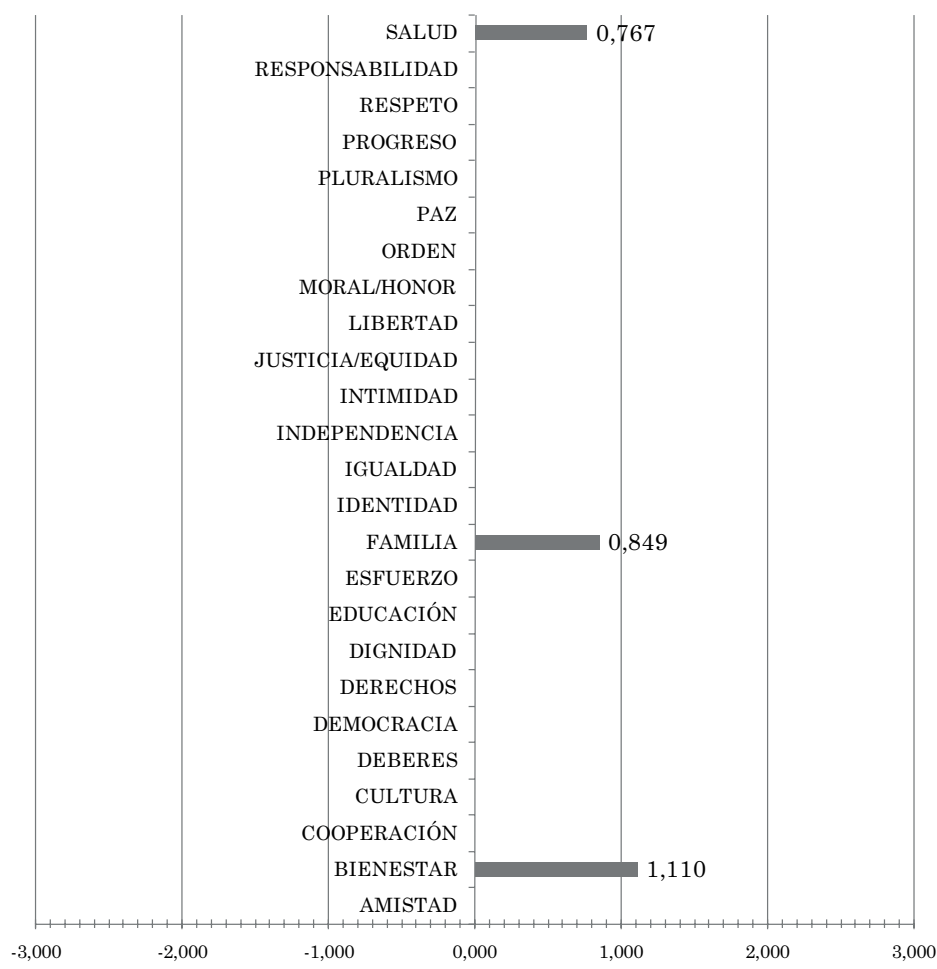

\section{Confiabilidad}

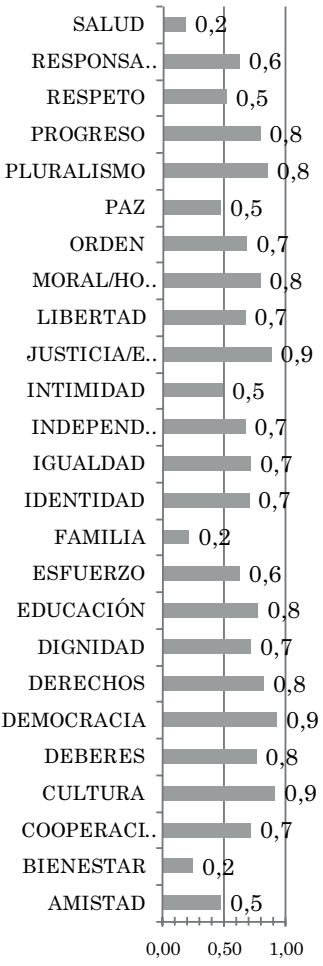

\section{Confiabilidad}

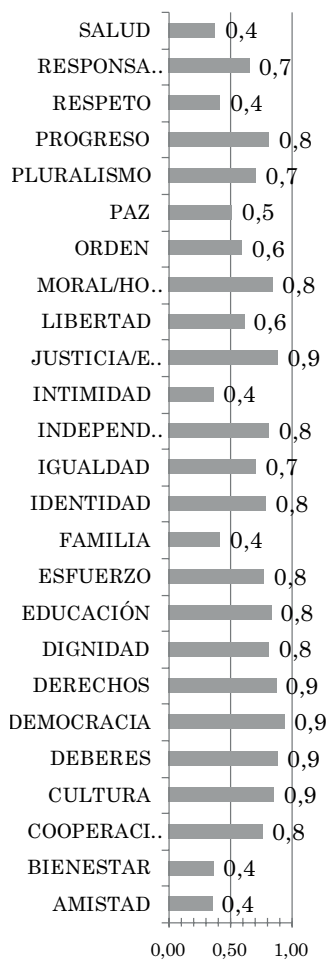

Figura 6. Carga global y confiabilidad del spot 6 (All Bran), sobre el espectro de valores del Protocolo EVA, en grupos con y sin trastornos de la conducta alimentaria. Barcelona, 2013.

Fuente: Elaboración propia.

TCA = Trastornos de la conducta alimentaria. 
Grupo con TCA | Carga global $=-\mathbf{0 , 1 4 2}$

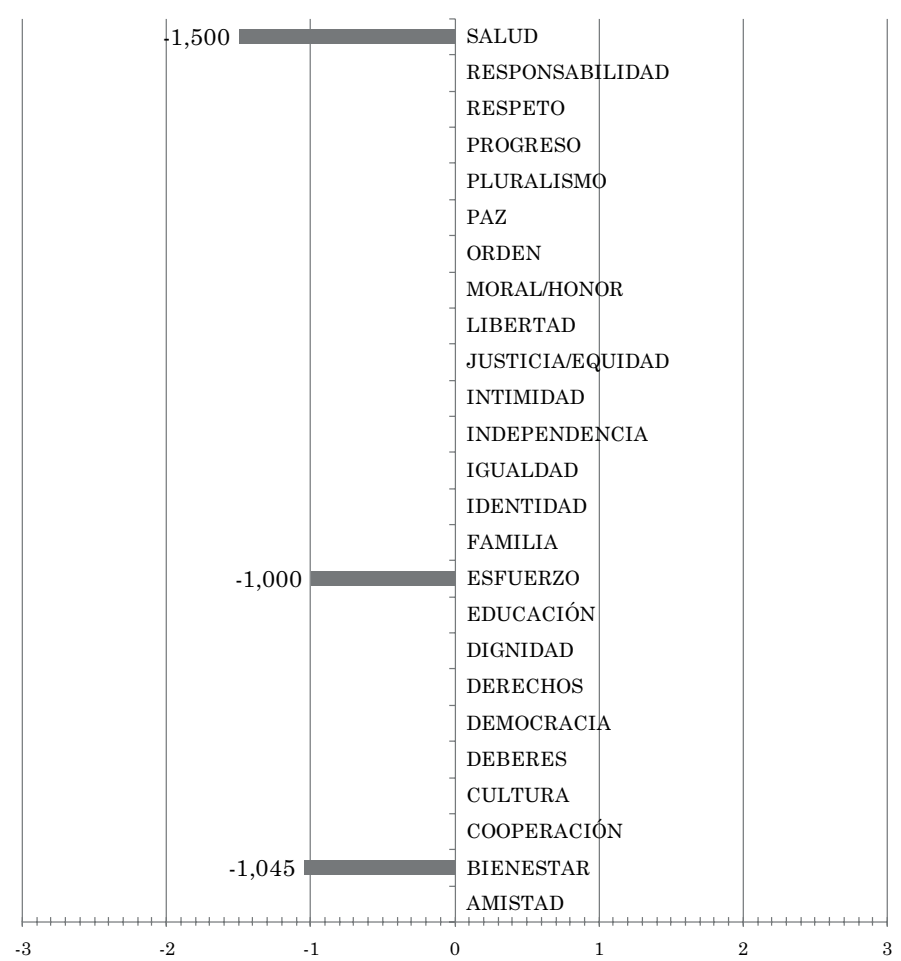

Grupo sin TCA | Carga global $=\mathbf{0 , 0 4 7}$

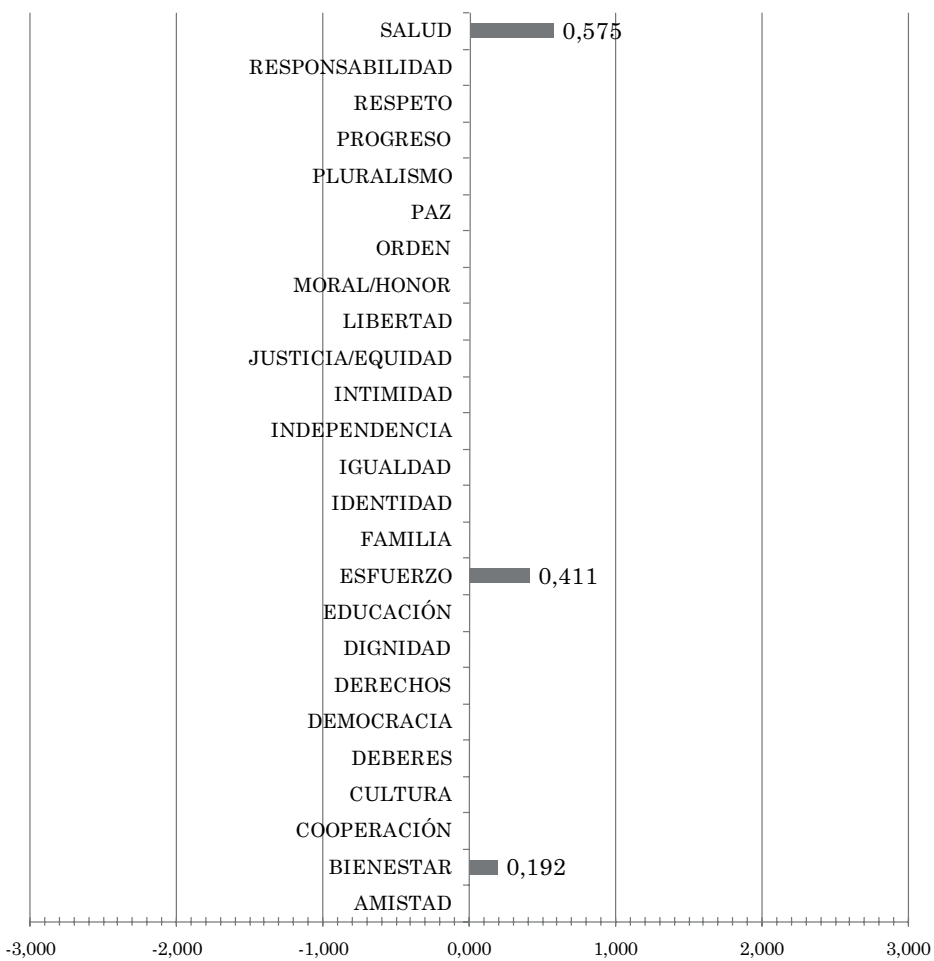

\section{Confiabilidad}

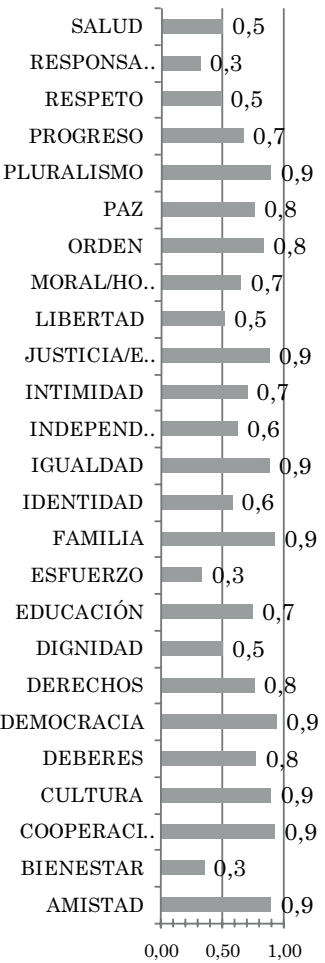

\section{Confiabilidad}

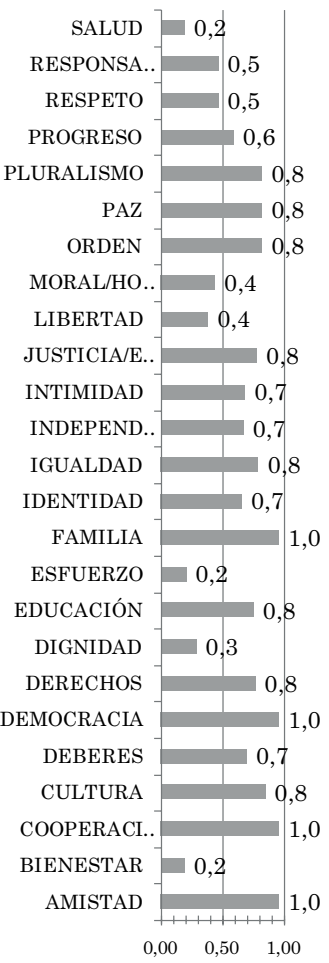

Figura 7. Carga global y confiabilidad del spot 7 (Special K), sobre el espectro de valores del Protocolo EVA, en grupos con y sin trastornos de la conducta alimentaria. Barcelona, 2013.

Fuente: Elaboración propia.

TCA = Trastornos de la conducta alimentaria 


\section{DISCUSIÓN}

Nuestros datos muestran que, efectivamente, la recepción de los valores sociales, educativos y humanos en los spots televisivos sobre productos alimentarios (66) es distinta entre el grupo con y sin TCA, en consecuencia, podemos afirmar que se cumple la hipótesis principal. Las diferencias localizadas consisten en que puede observarse una valoración opuesta de los dos grupos de sujetos de la muestra (con y sin TCA) respecto a la influencia (favorable o desfavorable) de tres de los spots (los que utilizan estrategias de imagen corporal) en la percepción de los valores. Esta misma observación señala, también, el cumplimiento de la segunda subhipótesis, pero no de la primera, ya que los datos indican una coincidencia general entre los valores que los dos grupos identifican como presentes en los spots.

La alta coincidencia entre los valores percibidos en los spots por los jóvenes con y sin TCA expresa el buen funcionamiento del Protocolo EVA para medición de valores en productos comunicativos. Además, el estadístico paramétrico t de Student ha confirmado las diferencias significativas entre ambos grupos en determinados valores. Esto nos permite hacer una interpretación de la coherencia general y las diferencias puntuales en determinados spots y determinados valores.

En el spot 1, observamos coherencia entre los dos grupos, tanto en la identificación de los valores como en el grado de la intensidad percibida, tal y como se puede ver en el espectro de la Figura 1. Únicamente hay diferencias en dos valores no recogidos por la t de Student. Por una parte, los jóvenes con TCA ponen el enfoque en la cooperación o ayuda entre los protagonistas del spot (los monos) mientras que los jóvenes sin TCA prestan más atención al esfuerzo de aprendizaje. Por otra, el valor moral-honor no es considerado como presente por el grupo con TCA, pero sí lo es, y está considerado positivamente, por el grupo sin TCA. Sin embargo, en general, excepto en el caso del valor moral-honor, los valores representados -incluyendo la cooperación y la educación- tienen medias muy similares, esto es, sin diferencias significativas. Al ser un spot sin referencias a la imagen corporal, parece lógico que el espectro de valores muestre un resultado con medias similares entre ambos grupos en los valores principales que lo definen: amistad, bienestar, cooperación, esfuerzo y educación.

En los spots 2, 3 y 5 (también sin referencias a la imagen corporal) ocurre lo mismo: el espectro de valores de cada grupo (ver Figura 2, 3 y 5), es muy similar: presencia de mismos valores y asignación del mismo sentido a la intensidad -contenido favorable al valor (datos positivos) o contenido desfavorable al valor (datos negativos)-, con el matiz de que se observa mayor intensidad en las valoraciones de los sujetos sin TCA. Las cargas de valor globales de nuevo tienden a ser mayores en el caso de los jóvenes sin TCA. Aunque la motivación no ha sido estudiada en esta investigación, los datos obtenidos indican claramente mayor sensibilidad en los jóvenes sin TCA para la percepción de valores en la publicidad.

Por su parte, los spots 4, 6 y 7, que emplean estrategias de imagen corporal (dietética y adelgazamiento), aportan el segundo patrón encontrado: ambos grupos de sujetos perciben la presencia de los mismos valores (normalmente bienestar, salud, esfuerzo y familia), pero ahora cada grupo valora los contenidos de los tres spots con intensidades de signo opuesto (negativo en el caso del grupo con TCA y positivo en el caso del grupo sin TCA). Al parecer, a los sujetos sin TCA les cuesta percibir el valor salud en estos spots ya que hay muy poco consenso en su valoración (confiabilidades bajas), en cambio, los sujetos con TCA aportan respuestas con un juicio claramente negativo. Así, mientras el grupo con TCA presenta respuestas reactivas que revelan cierta capacidad para interpretar las consecuencias negativas que conllevan este tipo de tramas sobre la salud y el bienestar propios, el grupo sin TCA se queda con el mensaje explícito que justifica la delgadez y parece aceptarlo sin llegar más allá. Esta interpretación de los resultados resulta coherente con la intensa educación sociocultural, psicológica, mediática y publicitaria que recibe el grupo de jóvenes con TCA mientras permanecen internos en el Institut de Trastorns Alimentaris de Barcelona.

El último spot (Figura 7, Special K) es el que aporta evidencias más claras del problema social y mediático, pues se trata del spot más directo y agresivo: se rechaza una pequeña ensaimada en el desayuno como forma de mantener la línea. En este caso, los tres valores recurrentes en las 
estrategias creativas de los productos alimentarios (salud, esfuerzo y bienestar) son evaluados de forma radicalmente opuesta por el grupo con y sin TCA. Resulta relevante destacar que, en la valoración de este anuncio, el grupo con TCA muestra confiabilidades altas, lo que indica que estos sujetos responden de forma convencida y mayoritaria; mientras que los jóvenes sin TCA parecen responder con más dudas porque intuyen que el mensaje no vehicula positivamente y de forma clara estos valores.

\section{CONCLUSIONES}

Los resultados obtenidos muestran que la percepción de valores en la publicidad tiene un papel determinante en el grave problema social que representan las conductas alimentarias alteradas por la imagen corporal de las personas actualmente.

Se han mostrado evidencias del gran consenso en la percepción de valores como amistad, igualdad, seguridad, educación, progreso, etc., en los spots de alimentación en general entre personas con y sin TCA, pero hay importantes diferencias en spots sobre productos alimentarios con estrategias de imagen corporal, particularmente en la evaluación positiva o negativa de los valores salud y bienestar. En general, se trata de mensajes que claramente incentivan conductas poco saludables (no cenar, el sentimiento de culpa por desayunar una pequeña ensaimada, la obsesión por contar calorías...), por lo que es significativo que el grupo con TCA los valore negativamente y que el grupo sin TCA los valore positivamente, en especial, los valores salud y bienestar $y$, en ocasiones, esfuerzo. Todo esto nos lleva a deducir que los primeros han aprendido a interpretar este tipo de mensajes, por las consecuencias graves de la enfermedad que están sufriendo y por la formación y terapia que reciben en el centro en el que se encuentran internos, y que los segundos hacen una interpretación de estas publicidades perfectamente integrada en las pautas comerciales del contexto social.

Por un lado, los sujetos sin TCA no han detectado el efecto negativo en contra de la salud y del bienestar del comportamiento que proponen estos spots y parecen incapaces de discernir los verdaderos objetivos de los spots analizados, porque han asumido totalmente los códigos mediático-publicitarios del orden social y económico imperante. En consecuencia, la población universitaria española actual presenta una baja capacidad para prever los efectos nocivos de los mensajes determinados por intereses comerciales.

Por otro lado, el grupo de sujetos con TCA son jóvenes que, en primer lugar, se encuentran en un centro en el que reciben una educación mediática específica para este tipo de mensajes. El hecho de tratarse de enfermas internas por causa de este tipo de conductas las hace más sensibles a estas cuestiones; esto explicaría la fuerte intensidad negativa con la que evalúan los spots con contenidos basados en estrategias de imagen corporal respecto a la salud, el bienestar y el esfuerzo. Esta respuesta puede estar determinada, también, por sus situaciones personales, al tratarse de individuos de alto riesgo y, por tanto, altamente sensibilizados.

Se puede concluir, además, que el uso de estrategias que hemos denominado "de imagen corporal" por parte de la publicidad va contra los valores contenidos en la Declaración Universal de Derechos Humanos y las constituciones de los países democráticos. Como consecuencia, consideramos que los resultados de este estudio deberían hacer tomar conciencia a las autoridades públicas sobre la importancia de controlar estas disfunciones sociales en relación con la transmisión de valores a través de la publicidad, particularmente, en la de alimentación dirigida a jóvenes.

Como se ha visto en los estudios referenciados, el papel de los medios en general es muy importante en la instauración de una conciencia colectiva, una cultura avanzada y una educación integral en valores y hacia una salud íntegra basada precisamente en los conceptos de bienestar y esfuerzo. Esta línea aplicada, inaugurada por Grunert, debe perseguir la integralidad de una educación mediática basada en la identificación y el refuerzo en la formación en valores, y no solo una alfabetización mediática determinada por la normalización y naturalización de cánones construidos social y normativamente por los grandes grupos de presión occidentales.

Por último, la coherencia global de los resultados valida el funcionamiento de la herramienta. Se trata de una herramienta de medición de 
percepciones y evaluación de valores en poblaciones receptoras de material publicitario audiovisual: el "Protocolo EVA" (64), un procedimiento científico validado que permite medir objetivamente y evaluar comparativamente la carga de valores humanos educativos y sociales que transmite un mensaje, o una serie de mensajes, a un público predeterminado. Su buen funcionamiento en el caso que presentamos indica su gran potencial y su utilidad como herramienta de medida en problemas de investigación asociados a la carga, la transmisión, la producción y la destrucción de valores en cualquier tipo de mensajes y ámbitos. Esta herramienta puede convertirse en un estándar para el control de mensajes publicitarios sobre alimentación, la detección de riegos en trastornos mentales, y la evaluación de los efectos de un aprendizaje que contribuya a compensarlos.

\section{AGRADECIMIENTOS}

Este estudio se enmarca en el proyecto con referencia CSO2012-33170, financiado por el Ministerio de Economía y Competitividad de España.

\section{REFERENCIAS BIBLIOGRÁFICAS}

1. Oliveira LL, Hutz, CS. Transtornos alimentares: o papel dos aspectos culturais no mundo contemporâneo. Psicologia em Estudo. 2010;15(3):575-582.

2. Gismero-González ME. Factores causales de los trastornos de la conducta alimentaria atribuidos por profesionales sanitarios. Acción Psicológica. 2012;9(2):77-86.

3. Martín M. Historia mediática de la anorexia. Icono14. 2010;8(3):45-61.

4. Plaza JF. Medios de comunicación, anorexia y bulimia. Icono14. 2010;8(3):62-83.

5. Díaz-Soloaga $P$, Quintas-Froufe $N$, Muñiz C. Cuerpos mediáticos versus cuerpos reales: Un estudio de la representación del cuerpo femenino en la publicidad de marcas de moda en España. Icono14. 2010;8(3):244-256.

6. Pichot P, López-Ibor JJ, Valdés M. Manual diagnóstico y estadístico de los trastornos mentales. 4a ed. Barcelona: Masson; 1997.

7. Chinchilla A. Anorexia y bulimia nerviosas. Madrid: Ergon DL; 1994.
8. Soriano J, Sedó V. Trastornos de la conducta alimentaria: ¿Síndromes culturales? Bioètica \& Debat. 2008;14(52):9-12.

9. Ida SW, Silva RN. Transtornos alimentares: uma perspectiva social. Revista Mal Estar e Subjetividade. 2007;7(2):417-432.

10. Abramovitz BA, Birch LL. Five-year-old girls' ideas about dieting are predicted by mothers' dieting. Journal of the Academy of Nutrition and Dietetics. 2000;100(10):1157-1163.

11. Davison KK, Markey CN, Birch LL. A longitudinal examination of patterns in girls' weight concerns and body dissatisfaction from ages 5 to 9 years. International Journal Eating Disorders. 2003;33:320-332.

12. Phares V, Steinberg AR, Thompson K. Gender differences in peer and parental influences: Body image disturbance, self-worth, and psychological functioning in preadolescent children. Journal of Youth and Adolescence. 2004;33:421-429.

13. Skemp-Arlt KM, Rees KS, Mikat RP, Seebach EE. Body image dissatisfaction among third, fourth, and fifth grade children. Californian Journal of Health Promotion. 2006;4(3):58-61. 
14. Mancilla A, Vázquez R, Mancilla JM, Amaya A, Álvarez G. Body dissatisfaction in children and adolescents: A Systematic review. Revista Mexicana de Trastornos Alimentarios. 2012;13(1):62-69.

15. Bird EL, Halliwell E, Diedrichs PhC, Harcourt D. Happy Being Me in the UK: A controlled evaluation of a school-based body image intervention with preadolescent children. Body Image. 2013;10(3):326-334.

16. Hargreaves DA, Tiggemann M. Idealized media images and adolescent body image: "Comparing" boys and girls. Body image. 2004;1(4):351-361.

17. Fischler C. El (h)omnívoro: El gusto, la cocina y el cuerpo. Barcelona: Anagrama; 1995.

18. Harrison K, Cantor J. The relationship between media consumption and eating disorders. Journal of Communication. 1997;47(1):40-67.

19. Field $A E$, Cheung $L$, Wolf $A M$, Herzog $D B$, Gortmaker SL, Golditz GA. Exposure to the mass media and weight concerns among girls. Pediatrics. 1999;103(3):E36.

20. Botta RA. Television images and adolescent girls' body image disturbance. Journal of Communication. 1999;49:22-41.

21. Groesz LM, Levine MP, Murnen SK. The effect of experimental presentation of thin media images on body satisfaction: A meta-analytic review. International Journal of Eating Disorders. 2002;31(1):1-16.

22. Bordieu P. Distinction: a social critique of the judegment of taste. Cambridge: Mass: Harvard University Press; 1984.

23. Carrillo MV, Jiménez-Morales $M$, Sánchez M. Medios de comunicación y culto al cuerpo. Mexico: Pearson; 2013.

24. Bernárdez A. Representaciones de lo femenino en la publicidad: Muñecas y mujeres: entre la materia artificial y la carne. Cuadernos de Información y Comunicación. 2009;14:269-286.

25. Cáceres Zapatero MDE, Díaz-Soloaga P. La representación del cuerpo de la mujer en la publicidad de revistas femeninas. Estudios sobre el Mensaje Periodístico. 2009;14:309-327.

26. Lage A. Estereotipos visuales femeninos en la fotografía publicitaria en los productos dirigidos a la apariencia de mujer en las revistas de moda [Disertación]. Barcelona: Universidad Autónoma de Barcelona; 2013.
27. Halliwell E, Dittmar H. Does size matter? The impact of model's body size on women's body-focused anxiety and advertising effectiveness. Journal of Social and Clinical Psychology. 2004;23(1):104-122.

28. Jiménez-Morales M. De l'estereotip publicitari adult a la realitat preadolescent: Influència de la publicitat en els trastorns del comportament alimentari en nens i nenes de 8 a 12 anys [Tesis de Maestría]. Barcelona: Universitat Pompeu Fabra; 2006.

29. Boyland EJ, Harrold JA, Kirkham TC, Halford JCG. The extent of food advertising to children on UK television in 2008. International Journal of Pediatric Obesity. 2011;6:455-461.

30. Bell BT, Lawton R, Dittmar H. The impact of thin models in music videos, on adolescent girls' body dissatisfaction. Body Image. 2007;4:137-145.

31. Harper B, Tiggemann M. The effect of thin ideal media images on women self objetification, mood and body image. Sex Roles. 2008;58:649-657.

32. Myers $P$, Biocca $M$. The elastic body image: The effect of television advertising and programming on body image distortion in young women Journal of Communication. 1992;42(3):103-133.

33. Hamilton K, Waller G. Media influences on body size estimation in anorexia nervosa and bulimia: an experimental study. British Journal of Psychiatry. 1993;162:837-840.

34. Byrd-Bredbenner C, Grasso D. What is television trying to make children swallow?: Content analysis of the nutrition information in prime-time advertisements. Journal of Nutrition Education. 2000;32(4):187-195.

35. Harrison K, Marske AL. Nutritional content of foods advertised during the television programs children watch most. American Journal of Public Health. 2005;95(9):1568-1574.

36. González-Díaz C. La categoría de producto y el mensaje transmitido en la publicidad infantil de alimentos. Revista Latina de Comunicación Social. 2008;63:480-491.

37. Kelly B, Halford JCG, Boyland EJ, Chapman K, Bautista-Castaño I, Berg C, Summerbell C. Television food advertising to children: A global perspective. American Journal of Public Health. 2010;100(9):1730-1736.

38. Tufte B, Ekström KM. Children, media and consumption: On the front Edge. Göteborg: Nordicom; 2007. 
39. Nemeroff CJ, Stein RI, Diehl NS, Smilack KM. From the Cleavers to the Clintons: Role choices and body orientation as reflected in magazine article content. International Journal of Eating Disorders. 1994;16:167-176.

40. Grabe S, Ward LM, Hyde JS. The role of the media in body image concerns among women: A meta-analysis of experimental and correlational studies. Psychological Bulletin. 2008;134(3):460-476.

41. Levine MP, Murnen SK. Everybody knows that mass media are/are not [pick one] a cause of eating disorders: A critical review of evidence for a causal link between media, negative body image and disordered eating in females. Journal of Social and Clinical Psychology. 2009;28:9-42.

42. Organización Mundial de la Salud. Constitución. Ginebra: Organización Mundial de la Salud; 1985.

43. Escámez Sánchez J. Valores, actitudes y habilidades en la educación para la salud. Educación XX1. 2001;(4):41-59.

44. Quero Mohamed S. Nuevas propuestas educativas: Salud y Valores. Ceuta: Centro de Profesores y Recursos de Ceuta; 2008.

45. Carreras Port A. Coeducar des del bressol; La construcció de les identitats de gènere a la primera infancia. Barcelona: Diputació de Barcelona; 2011.

46. Kahle LR, Beatty SE, Homer PM. Alternative measurement approaches to consumer values: the list of values (LOV) and values and lifestyles (VALS). Journal of Consumer Research. 1986;13:405-409.

47. Grunert SC. Ein Inventar zur Erfassung von Selbstaussagen zum Ernährungsverhalten. Diagnostica. 1989;35(2):167-179.

48. Maslow AH. Motivation and personality. 3rd ed. New York: Harper \& Row; 1987.

49. van Strien T, Frijters JER, Berger GPA, Defares $P B$. The dutch eating behavior questionnaire for the assessment of restrained, emotional and external eating Behavior. International Journal of Eating Disorders. 1986;5:295-315.

50. Grunert SC. The influence of values on compensatory eating behaviour. British Food Journal. 1991;93(9):4-9.

51. Lobstein T. Cereales peligrosos: La verdad sobre la publicidad de alimentos dañinos dirigidos a los niños. London: Consumers International; 2008.
52. Drumwright ME, Murphy PE. How advertising practitioners view ethics: moral muteness, moral myopia, and moral imagination. Journal of Advertising. 2004;33(2):7-24.

53. Pollay RW. The distorted mirror: Reflections on the unintended consequences of advertising. Advertising \& Society Review. 2000;1(1).

54. Andrews JC. The dimensionality of beliefs toward advertising in general. Journal of Advertising. 1989;18(1):26-35.

55. Scherman A, Arriagada A, Valenzuela S. Student and environmental protests in Chile: The role of social media. Politics; 2015;35(2):151-171.

56. Vaterlaus JM, Patten EV, Roche C, Young JA. \#Gettinghealthy: The perceived influence of social media on young adult health behaviors. Computers in Human Behavior. 2015;(45):151-157.

57. Lull J. The social uses of television. Human Communication Research. 1980;6(3):197-209.

58. Prendergast G, West DC, Yan LK. Eating Disorders-The Role of Advertising and Editorial. In: Proceedings of the 2002 Academy of Marketing Science (AMS) Annual Conference. Cham: Springer International Publishing; 2015. p. 175-178.

59. Lane SR, Fisher SM. The influence of celebrity chefs on a student population. British Food Journal. 2015;117(2):614-628.

60. Gracia Arnaiz MI. Género, "dieting" y salud un análisis transcultural de la incidencia de los trastornos del comportamiento alimentario entre las mujeres. Madrid: Instituto de la Mujer; 2006.

61. Bittencourt LJ, Almeida RA. Transtornos alimentares: patologia ou estilo de vida? Psicologia \& Sociedade. 2013;25(1):220-229.

62. Rokeach M. The nature of human values. New York: Free Press; 1973.

63. Schwartz S. Value priorities and behavior: applying a theory of integrated value systems. In: Seligman C, Olson J, Zanna M. The psychology of values: The Ontario Symposium. Mahwah: Lawrence Erlbaum; 1996.

64. Rodríguez Bravo A, Montoya Vilar N, Mas Manchón LL, Morales Morante F, Lopes da Silva E, Martins G, Peixoto M, Müller K. Medición y evaluación de valores en contenidos audiovisuales desde un abordaje interdisciplinar. Prisma Social Revista de Investigación Social. 2013;11:158-204. 
65. Montoya Vilar N, Rodríguez Bravo A, Mas Manchón LL. Calidad y evaluación de valores en la comunicación: Construcción de un inventario de valores para España y Brasil. XXXV Congresso Brasileiro de Ciências da Comunicação; sep 2012; Fortaleza, Brasil.
66. Casalé A, Añaños E. Efectos de la publicidad alimentaria y estética corporal en los sujetos con trastorno de la conducta alimentaria [Disertación]. Barcelona: Universidad Autónoma de Barcelona; 2013.

\section{FORMA DE CITAR}

Mas-Manchón L, Rodríguez-Bravo A, Montoya-Vilar N, Morales-Morante F, Lopes E, Añaños E, Peres R, Martínez ME, Grau A. Valores percibidos en la publicidad de alimentos por jóvenes con y sin trastornos de la conducta alimentaria. Salud Colectiva. 2015;11(3):423-444.

Recibido: 4 de noviembre de 2014 | Versión final: 9 de marzo de 2015 | Aprobado: 27 de abril de 2015

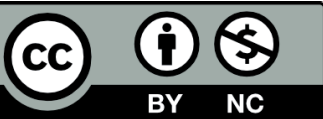

Este obra está bajo una licencia de Creative Commons Reconocimiento-NoComercial 4.0 Internacional. Reconocimiento - Permite copiar, distribuir y comunicar públicamente la obra. A cambio, se debe reconocer y citar al autor original. No Comercial - Esta obra no puede ser utilizada con finalidades comerciales, a menos que se obtenga el permiso.

http://dx.doi.org/10.18294/sc.2015.729 